\title{
CHROMOSOME PAIRING IN TRIPLOID FEMALES OF BOMBYX MORI ANALYZED BY THREE DIMENSIONAL RECONSTRUCTIONS OF SYNAPTONEMAL COMPLEXES.
}

\author{
by \\ SøREN WILKEN RASMUSSEN \\ Department of Physiology, Carlsberg Laboratory, \\ Gamle Carlsberg Vej 10 - DK-2500 Copenhagen, Valby
}

\begin{abstract}
Key words: Silkworm, pachytene, bivalents, trivalents, univalents, homologous and non-homologous pairing
\end{abstract}

\begin{abstract}
Chromosome pairing in triploid females of Bombyx mori was analyzed by serial sectioning and three dimensional reconstruction of synaptonemal complexes and unpaired lateral components in 11 nuclei covering the period from early to late pachytene. Two distinct phases of chromosome pairing with synaptonemal complex formation were revealed; one phase mediates pairing between homologous chromosomes and is followed by a second phase which is responsible for non-homologous pairing of univalents. Trivalent pairing of three homologues as well as bivalent interlocking appear to be corrected by dissolution and reassembly of the central regions of the synaptonemal complex before the initiation of or during the second pairing phase.
\end{abstract}

\section{INTRODUCTION}

A precise pairing of homologous chromosomes during early meiotic prophase is a prerequisite for crossing over, chiasma formation, and regular disjunction. The synaptonemal complex provides the structure which ensures this precise site-to-site matching of homologous chromosomes and the subsequent stabilization of the paired regions. In those cases where pairing has been analyzed by serial sectioning and three dimensional reconstructions of zygotene and pachytene nuclei $(2,6,7,15,21,25,28$, 56) it is apparent that pairing occurs with great precision. At pachytene, where the result of the pairing process can be analyzed, irregularities are the exception $(11,28)$ and a precise alignment of homologous chromosomes the rule.

After the synaptonemal complexes are shed from the bivalents, the association of homologous chromosomes which is essential for a regular disjunction, is mediated by chromatin bridges formed by non-sister chromatid exchanges $(10,37,39,52,53)$. Investigations in human spermatocytes have shown that small stretches of synaptonemal complex are retained in the bivalents at early metaphase I. This suggests that the synaptonemal complex in some cases continues to play a role in the association 
of homologous chromosomes after the majority of complexes is eliminated in early diplotene (23, Holm and RASMUSSEN, unpublished results).

In the absence of crossing over, substitute mechanisms are required to ensure a regular disjunction of the homologues at anaphase I. The synaptonemal complexes in Bombyx oocytes undergo an ultrastructural modification by addition of material to the lateral component. The modified synaptonemal complexes are retained by the bivalents until anaphase I. At anaphase I, the modified synaptonemal complexes are shed from the homologues and remain in the position of the metaphase plate $(18,30,34)$.

Several authors $(21,25,41,51,54,55)$ have proposed on the basis of ultrastructural or biochemical studies that the pairing of homologous chromosomes occurs in two steps: a primary attraction of homologous chromosomes, followed by stabilization of pairing by the formation of synaptonemal complexes.

Information on the mechanisms underlying the primary attraction and recognition of the homologous chromosomes and their subsequent intimate pairing is confined to the following relatively well-established facts. a) The chromosomes are distributed randomly in the nucleus or are contained in two different nuclei prior to the meiotic prophase $(15,28,33,56)$. b) A lateral component of the synaptonemal complex is organized in each chromosome before or during the pairing $(10,15,27,28,55,56)$. c) The ends of all lateral components attach to the nuclear envelope. d) The attachment sites are concentrated within a limited region of the nuclear envelope, the bouquet region $(10,15$, $21,19)$. e) The homologous chromosomes approach each other to a distance of approximately $200-300 \mathrm{~nm}(21,25,28,51,55,56)$. f) The synaptonemal complex is completed by the formation of the central region between the lateral components. The central region is formed from starting points near the attachment sites of the lateral components on the nuclear envelope $(25,28)$ and/or from starting points distributed along the chromosomes $(10,15,22)$. g) The attachment sites of the bivalents with completed synaptonemal complexes move away from the bouquet region and the chromosomes become uniformly distributed in the nucleus $(10,28)$.

Studies on chromosome pairing in haploid organisms $(5,8,36,47)$ have demonstrated that extensive, presumably non-homologous, chromosome pairing can occur, and in barley may include up to $60 \%$ of the lateral components. Synaptonemal complexes between non-homologous chromosomes are morphologically indistinguishable from complexes between homologous chromosomes (8). This supports the view that the specificity involved during primary recognition and/or subsequent formation of the synaptonemal complex can be suppressed, resulting in synapsis between non-homologous chromosome segments.

In the silkworm, Bombyx mori, both sexes possess synaptonemal complexes $(16,20,28)$ but crossing over and chiasma formation are limited to males $(42,43,44)$. Chromosome pairing during early meiotic prophase in diploid oocytes is normal, resulting at pachytene in 28 bivalents each having a continuous synaptonemal complex between the attachment sites on the nuclear envelope (28). In four nuclei at late zygotene five cases of interlocking were observed. Four of these cases involved interlocking of two bivalents, and in the fifth case an unpaired lateral component was trapped between unpaired lateral components of an otherwise completely synapsed bivalent $(28,29)$. At pachytene, no interlockings were revealed in six completely reconstructed nuclei, thus indicating that a correction of pairing is possible during the transition from zygotene to pachytene. In triploid males and females of Bombyx mori more than the haploid number $(n=28)$ of chromosome elements is present at metaphase I and both males and females are sterile due to an unequal distribution of the three chromosome sets at anaphase I (1). Autotetraploid males are also sterile and less than the expected 56 elements are found at metaphase I, while tetra-

Abbreviations: SC, Synaptonemal complex. LC, Lateral component 
ploid females are fertile and the expected 56 chromosome elements are present at metaphase $I(45,50)$. SEILER (35) showed that a different situation is encountered in triploid intersexual hybrids between tetraploid parthenogenetic females and bisexual diploid males of Solenobia triquetrella. In these triploid hybrids the haploid number $(n=31)$ of trivalents is present at metaphase $I$ indicating that the association of homologues persists until anaphase I.

The present paper aims to analyse further details in the process of chromosome pairing, and the possible subsequent correction of pairing, by an examination of triploid females of Bombyx mori. The addition of an extra set of chromosomes provides a competition between three homologous chromosomes, as normally only two homologous segments are combined by a synaptonemal complex at a given site. Triploidy allows a clear distinction between the primary recognition of homologues and their intimate pairing through the synaptonemal complex.

\section{MATERIALS AND METHODS}

The material for this study was kindly provided by the late professor B. L. Astaurov, Institute of Developmental Biology, Academy of Sciences USSR, Moscow. The triploid females $(2 n=84)$ were obtained from crosses between tetraploid females $(4 n=112)$ and diploid males $(2 n=56)$. The tetraploid female parents were produced by thermal activation of normal diploid eggs and were maintained as parthenogenetic clones by thermal activation of dissected eggs as described by ASTAUROV (1) and VEREISKAYA (49).

The procedure for removing the ovaries and their subsequent fixation, dehydration, and embedding has previously been described (28). Thick sections (2-4 microns) were cut and examined in the light microsope in order to identify regions in the ovary containing nuclei in the desired stage of development. Series of thin sections were cut, photographed at a primary magnification of 4-5.000 x, and reconstructed as described by Gillies (6). The pro-

\section{Table I}

Classification of 11 comptetely reconstructed pachytene nuclei 5 from triploid females of Bombyx mori according to developmental stage.

\begin{tabular}{|c|c|c|c|c|c|}
\hline $\begin{array}{l}\text { Nucleus } \\
\text { number a) }\end{array}$ & $\begin{array}{l}\text { Nuclear } \\
\text { vacuole }\end{array}$ & $\begin{array}{l}\text { Bivalents in } \\
\text { bouquet } b \text { ) }\end{array}$ & $\begin{array}{l}\text { Univalents in } \\
\text { bouquet b) }\end{array}$ & $\begin{array}{l}\text { All three } \\
\text { telomeres } \\
\text { associated c) }\end{array}$ & $\begin{array}{c}\text { SC or LC } \\
\text { attached to } \\
\text { nuclear envelope b) }\end{array}$ \\
\hline $\begin{array}{l}1 \\
2\end{array}$ & + & $\begin{array}{l}+++ \\
+++\end{array}$ & $\begin{array}{l}+++ \\
+++\end{array}$ & $\begin{array}{l}43 \\
48\end{array}$ & $\begin{array}{l}+++ \\
+++\end{array}$ \\
\hline $\begin{array}{l}3 \\
4\end{array}$ & + & $\begin{array}{l}++ \\
++\end{array}$ & $\begin{array}{l}++ \\
++\end{array}$ & $\begin{array}{r}20 \\
0\end{array}$ & $\begin{array}{l}++ \\
++\end{array}$ \\
\hline 5 & - & - & + & 2 & + \\
\hline $\begin{array}{l}6 \\
7 \\
8 \\
9\end{array}$ & $\begin{array}{l}- \\
- \\
-\end{array}$ & $\begin{array}{l}- \\
- \\
-\end{array}$ & $\begin{array}{l}++ \\
++ \\
+ \\
+\end{array}$ & $\begin{array}{l}0 \\
0 \\
0 \\
0\end{array}$ & $\begin{array}{l}+ \\
+ \\
- \\
-\end{array}$ \\
\hline $\begin{array}{l}10 \\
11\end{array}$ & - & - & - & $\begin{array}{l}0 \\
0\end{array}$ & - \\
\hline
\end{tabular}

a) the nuclei in each group are from one cell cluster with the exception of nucleus 9 which belongs to a separate cell cluster.

b) +++ , all; ++ , the majority; + , a minor fraction.

c) the lateral component of the telomere of the univalent chromosome is closer than $300 \mathrm{~nm}$ to the one lateral component of the synaptonemal complex. Maximal possible number is 56 . 
jected lengths were measured and the real length calculated using a Hewlett Packard digitizer (HP 9864A) and calculator (HP 9825A).

The results were based on 11 completely reconstructed oocyte nuclei covering the period from early pachytene to late pachytene.

\section{RESULTS}

\subsection{General comments}

The temporal sequence of the 11 completely reconstructed oocyte nuclei was established on the basis of the sequential changes in the fol- lowing cellular and nuclear characters (see Table I): a) The distribution of organnels (Golgi apparatus, mitochondria) in the cell. b) The morphology of the nuclear vacuoles. c) The distribution of the attachment sites of lateral components and synaptonemal complexes on the nuclear envelope. As previously noted (28), only two chromosomes can be identified unequivocally by morphological markers; the longest chromosome, number 1 , by a knob which is present from late zygotene to modified pachytene and chromosome 2 by the nucleolus organizer region. Traut (48) was able to iden-

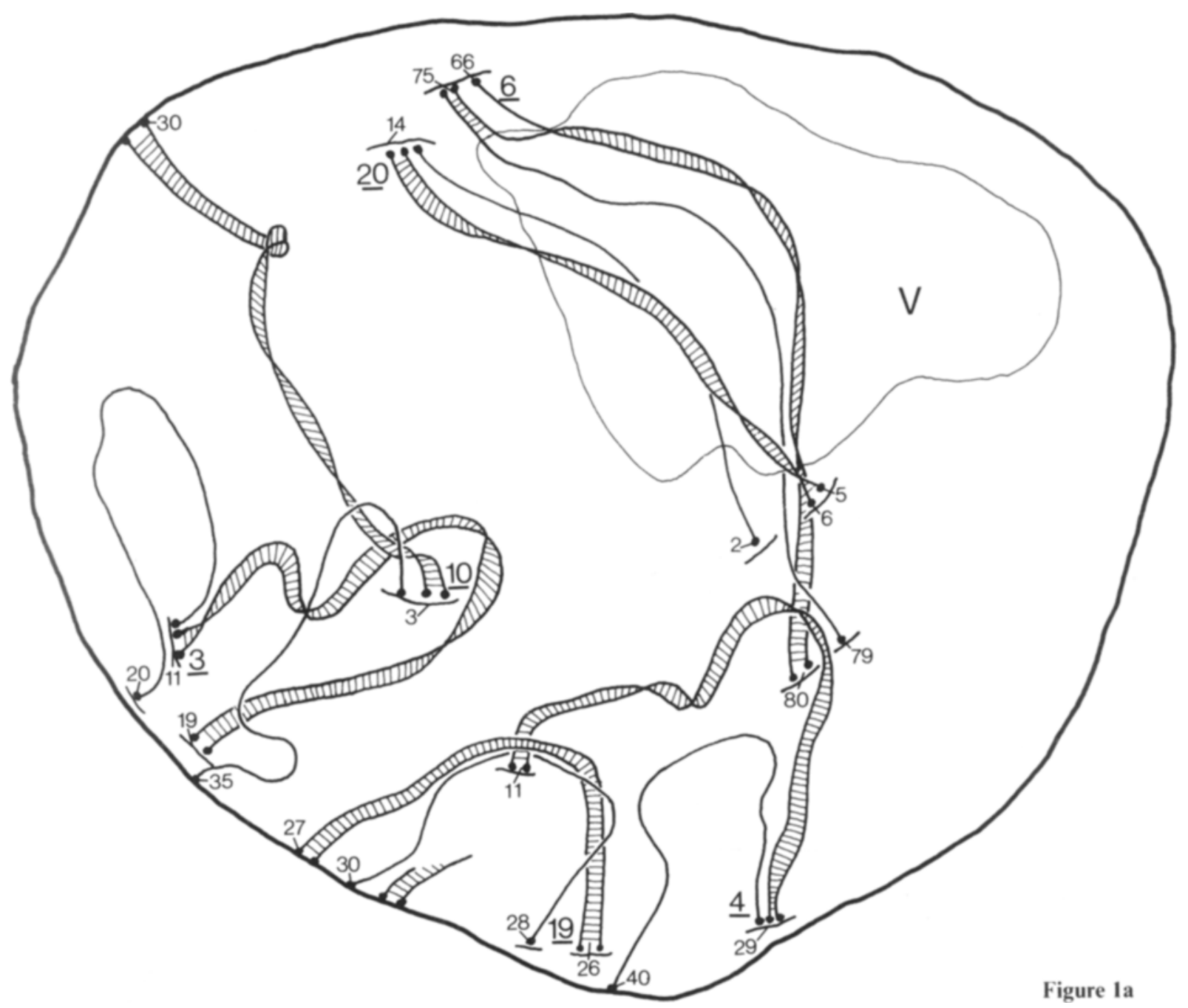


Figure la-d. A complete reconstruction of synaptonemal complexes and lateral components of the 84 chromosomes from a triploid Bombyx oocyte nucleus (number 1 ) at early pachytene. The chromosomes are all attached at both ends to the nuclear envelope in a bouquet opposite the nucleoius $(\mathrm{N})$ and the nuclear vacuole $(\mathrm{V})$. In the majority of the cases, two of the three homologous chromosomes have paired with a synaptonemal complex while the third homologue is roughly aligned with the bivalent, either along its entire length (e.g., chromosomes 6 and 20 in Figure a, 9 and 28 in Figure b, 2, 18, and 26 in Figure d) or only at one or both attachment sites on the nuclear envelope (e.g., 3, 4, and 10 in Figure a, 14 and 23 in Figure c). The only exception is chromosome 8 where the bivalent and its homologous univalent are located in different region of the nucleus (bivalent 8 is at the top and univalent 8 at the bottom in Figure c). In the lower left region of the nucleus (Figure c), the unpaired lateral component of chromosome 1 is trapped by stretches of bivalent 1 and by bivalent 14 , both with completed synaptonemal complexes. Also chromosomes 11, 22, and 23 (Figure c) are entangled. In four cases, synaptonemal complex formation has presumably started from both telomeres with two different homologous lateral components giving rise to a typical trivalent configuration (chromosome 6 in Figure a, 5 in Figure b, and 1 and 16 in Figure c). Note the two paired chromosome fragments in the lower left region of Figure a. (The underlined numbers designate the chromosomes which are also listed in Tables II and VI. The smaller numbers denote the section in which a particular telomere has been found.)

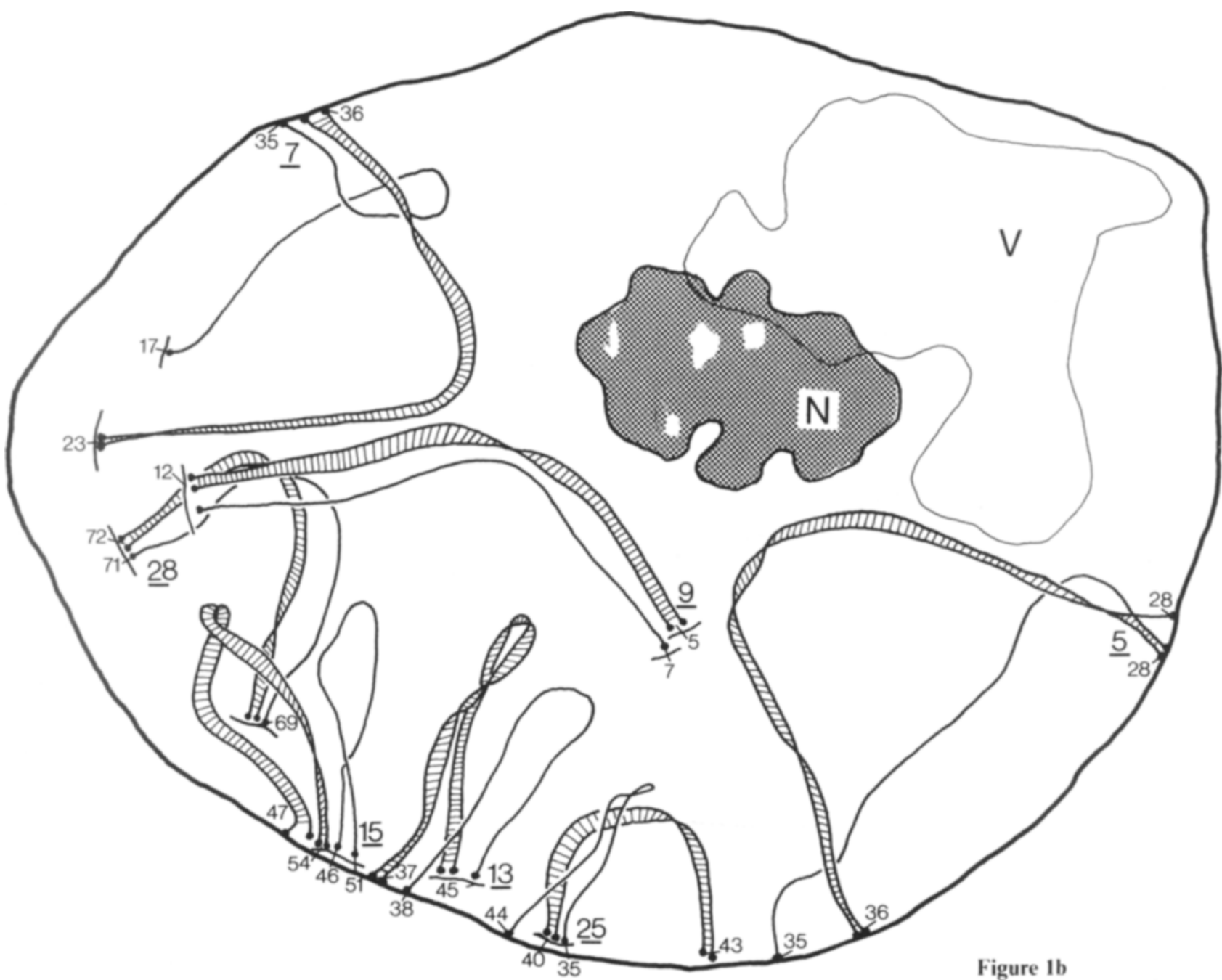


tify by light microscopical analysis of pachytene bivalents 6 bivalents including chromosomes 1 and 2 . The remaining 26 chromosomes can thus only be classified according to their length at the electron microscopical level. As some of the chromosomes are similar in length and the real length of a particular chromosome at pachytene is found to vary in different nuclei, an unequivocal idenfication of individual chromosomes other than chromosomes 1 and 2 was impossible. This is illustrated by the ranking of the latter two chromosomes in nuclei 5 to 11 in Table VI, if they were to be identified by length alone. The bivalent chromosome 1 is longer than chromosome 2 in all nuclei except 7 where it is shorter. With regard to the univalent chro- mosome 1 it is shorter than 2 in nuclei 8 and 10 but otherwise longer. On the other hand, homology is established in most cases unequivocally by synaptonemal complex formation between lateral components of equal length and at early to mid pachytene also by close association of at least one set of the three telomeres.

\subsection{Early pachytene (nuclei 1 and 2)}

Two nuclei belonging to the same cell cluster were analyzed. The stage was characterized by large nuclear vacuoles in the region opposite the chromosome bouquet, and by smaller multilayered invaginations of the inner membrane of the nuclear envelope in the region of chromosome attachment. On the cytoplasmic side of

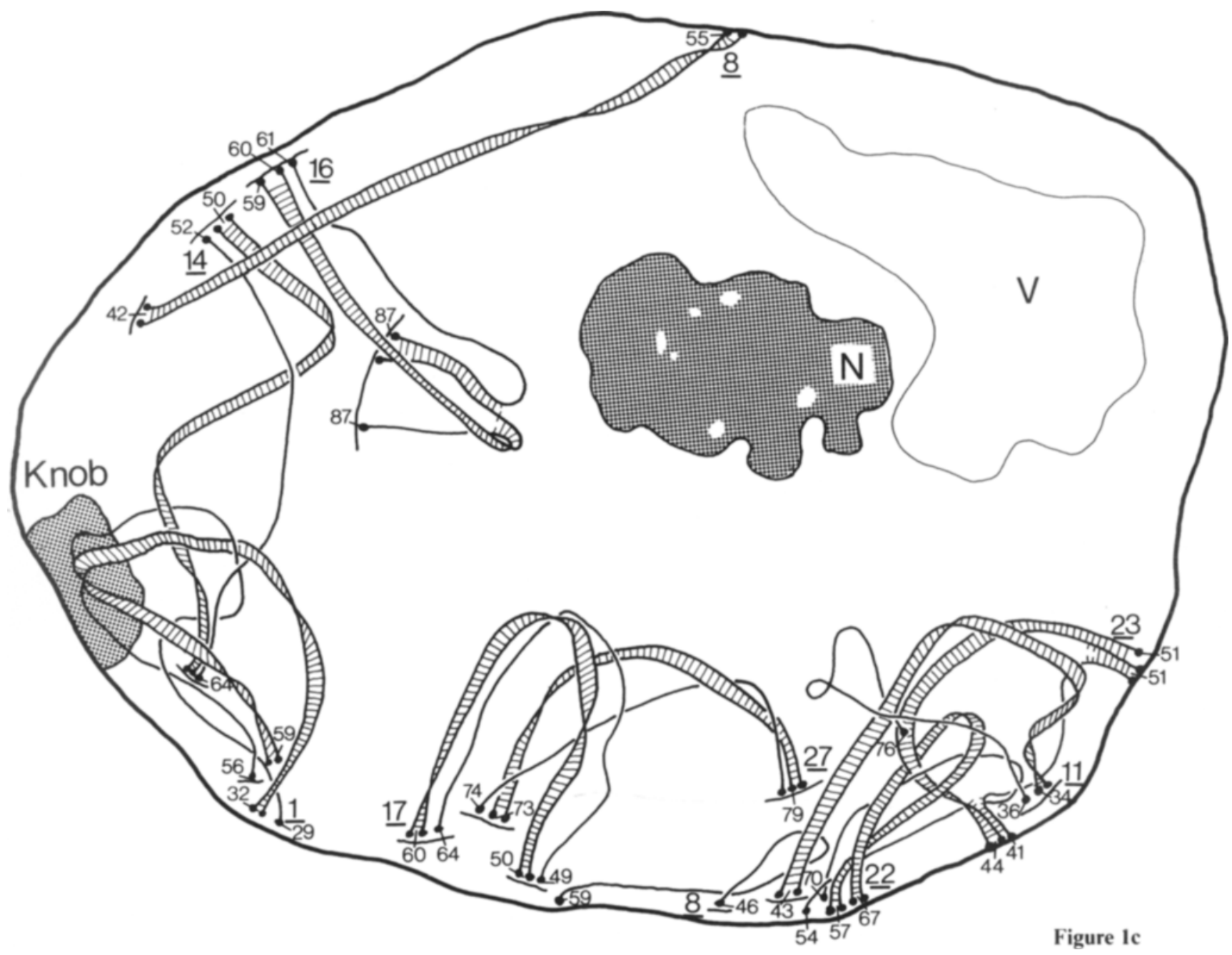


this region, a large number of mitochondria and Golgi apparatuses had accumulated. The lateral components of the synaptonemal complexes were attached at both ends to the nuclear envelope, the attachment sites being concentrated to a limited region of the nuclear envelope, forming the chromosome bouquet (Figure 1). With few exceptions, the three homologous telomeres were attached approximately $100-200 \mathrm{~nm}$ from each other. In most cases, two of the three homologous lateral components had combined into a synaptonemal complex, while the third lateral component was roughly aligned with the bivalent at a distance of about $200-500 \mathrm{~nm}$ (Figure 4). Near the attachment sites on the nuclear envelope the three homologous lateral components occasionally combined into what appeared to be double complexes at low magnification. As seen in Figures 2 and 5, the central regions of the double complexes, and especially those of the synaptonemal complex including the univalent, lack the ladder-like organization characteristic of completed central regions in more advanced nuclei. In seven cases the lateral component of the third homologue was exclusively associated with its homologous bivalent at one end. In three cases the bivalent was not associated at all with the third homologue. If synaptonemal complex formation starts simultaneously from both ends of a

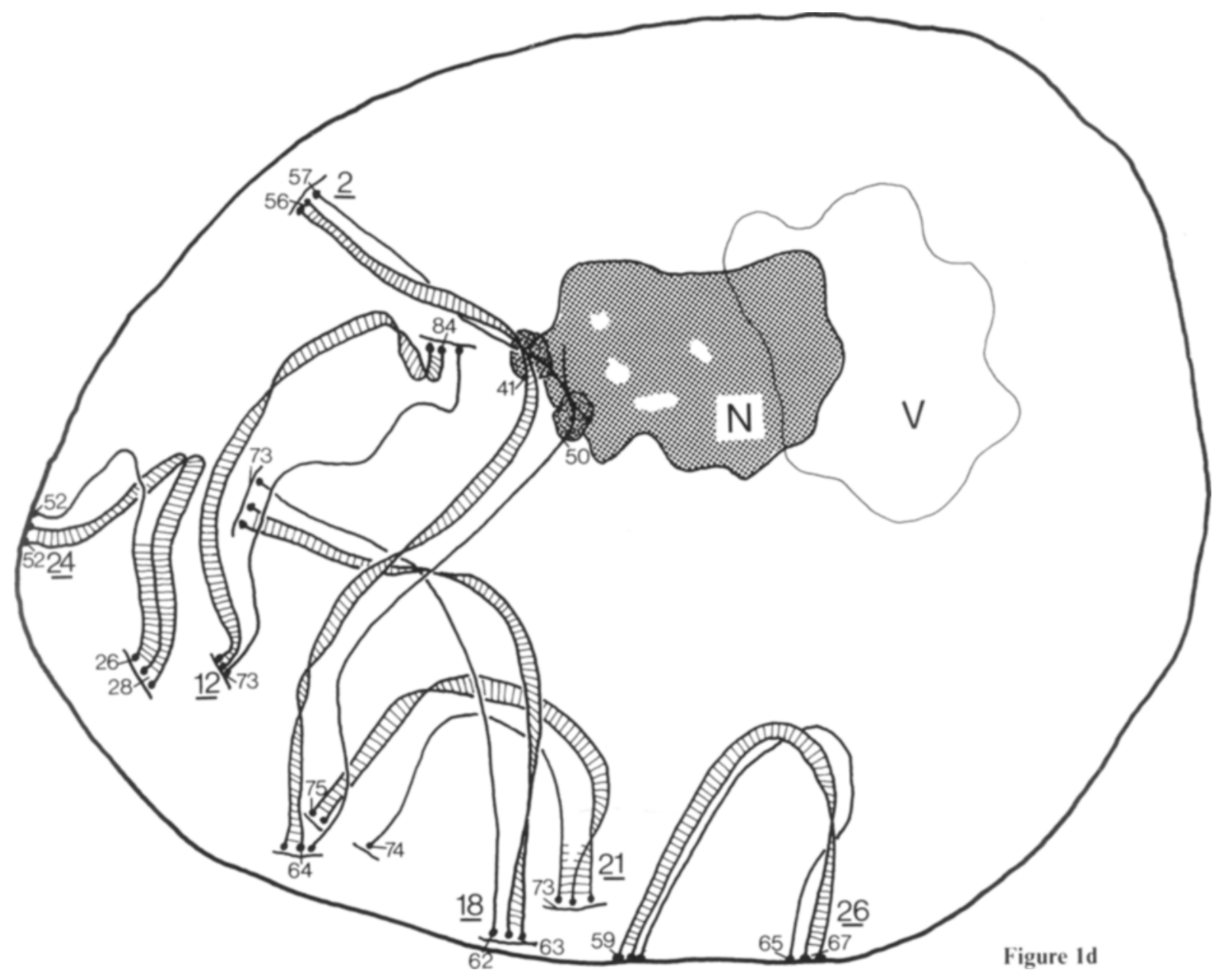


?

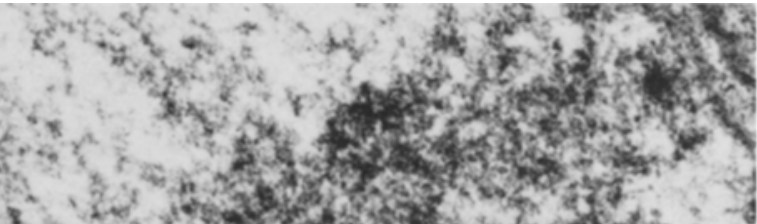
wh by 1020

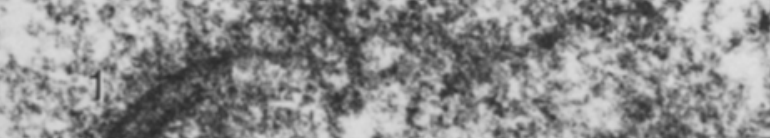

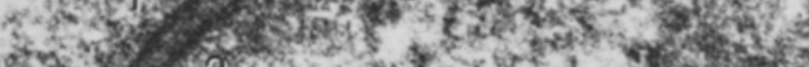

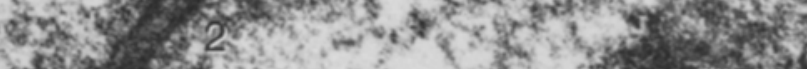
1.

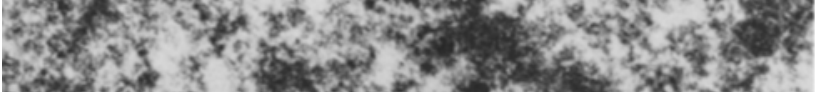

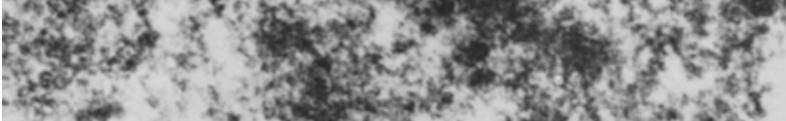

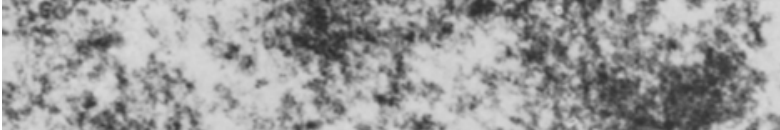

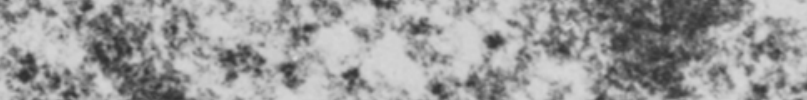

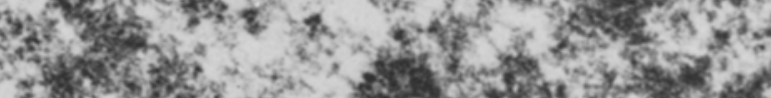

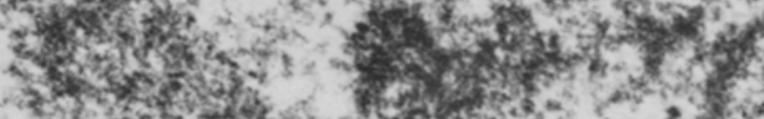

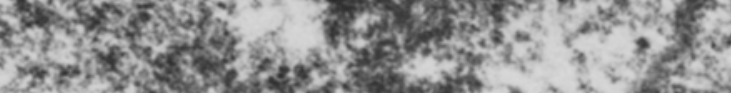

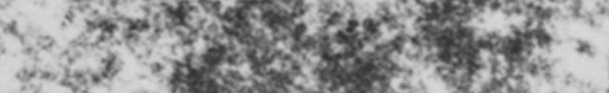

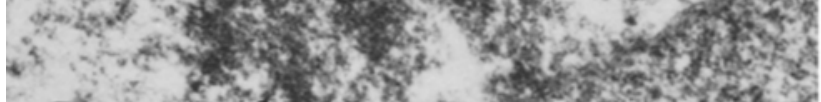

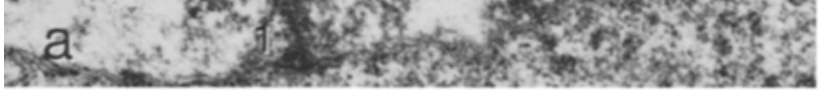

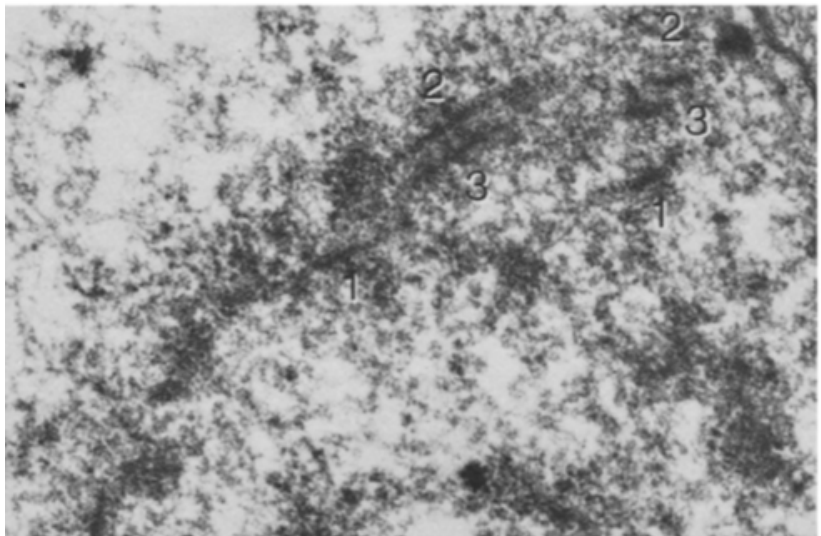

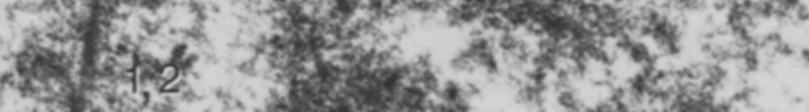

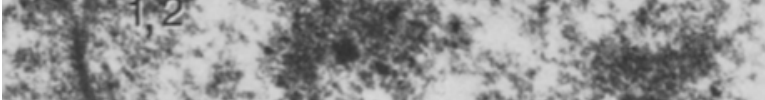

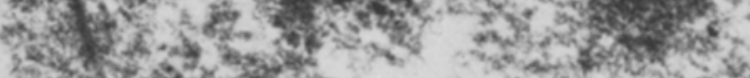

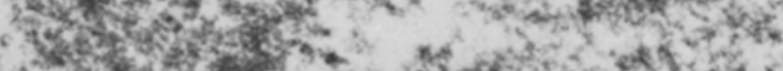
$x+2.45$ $-713.201 \%$

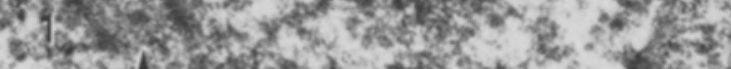

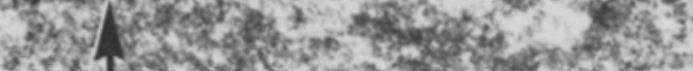

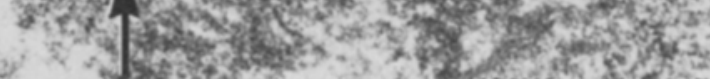

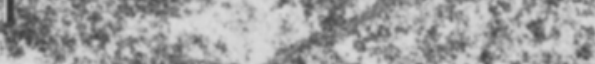

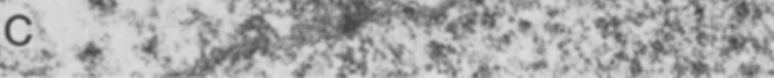

3.

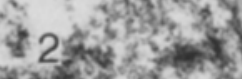

स.

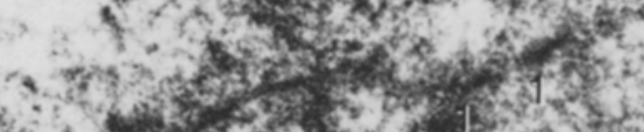

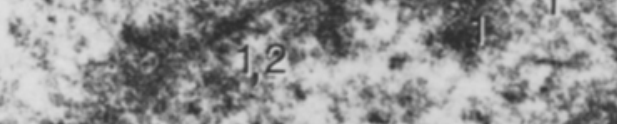
Sulesw

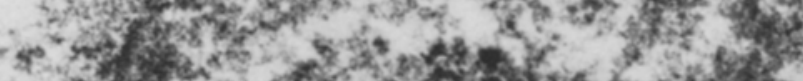

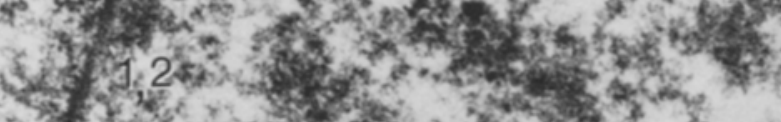

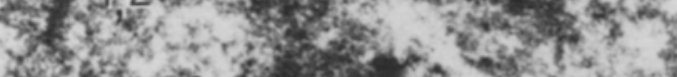

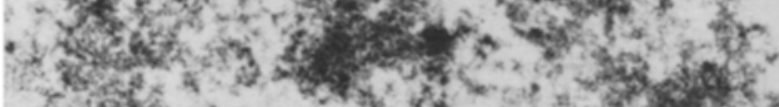

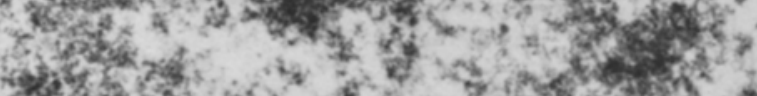

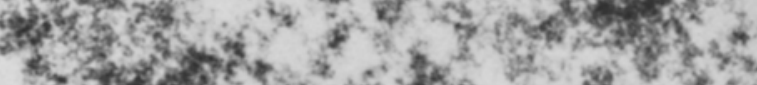

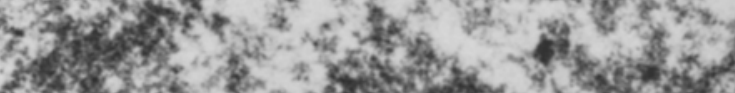

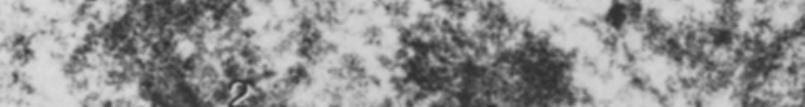

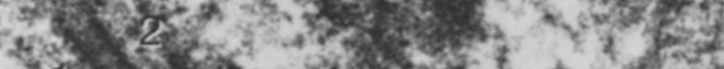

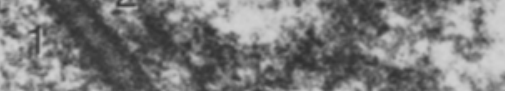

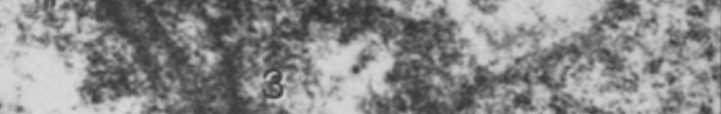

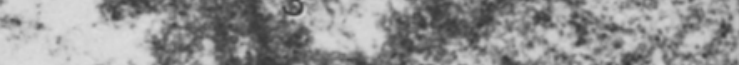

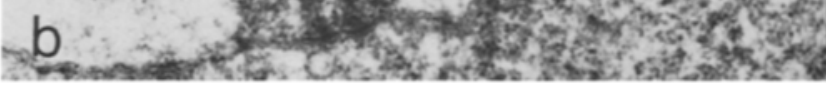

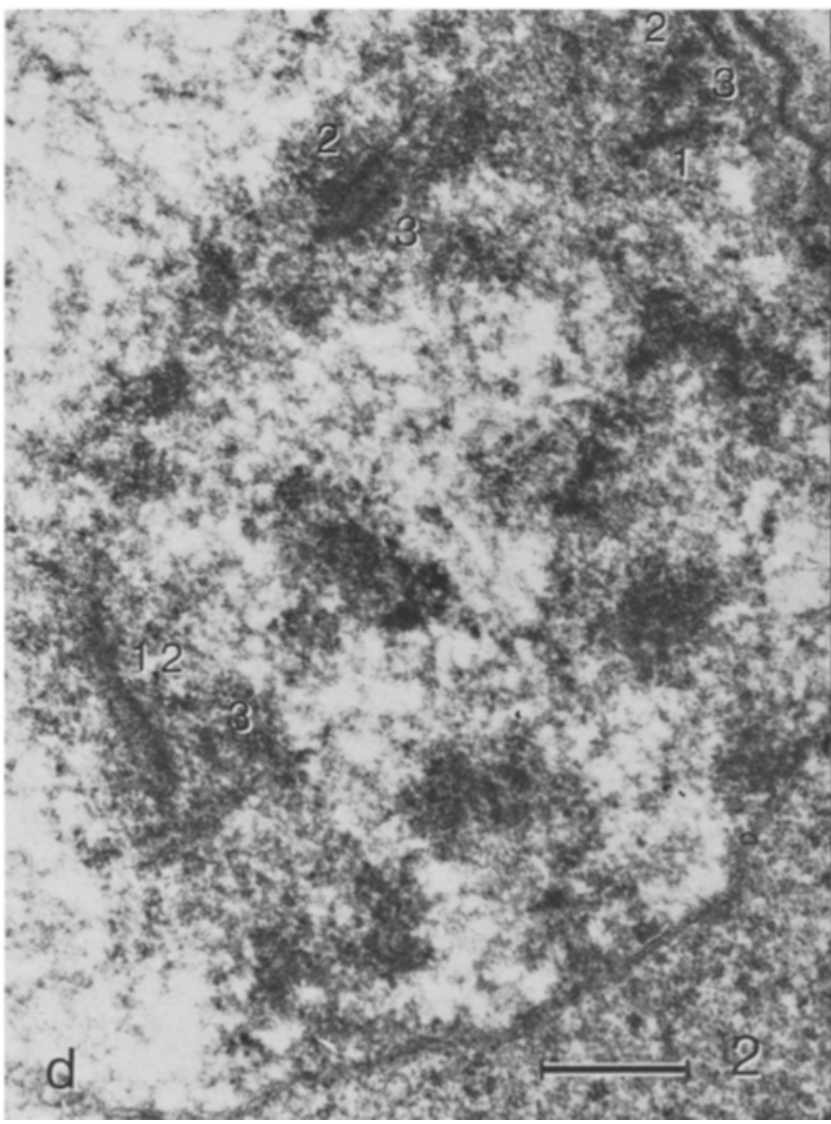



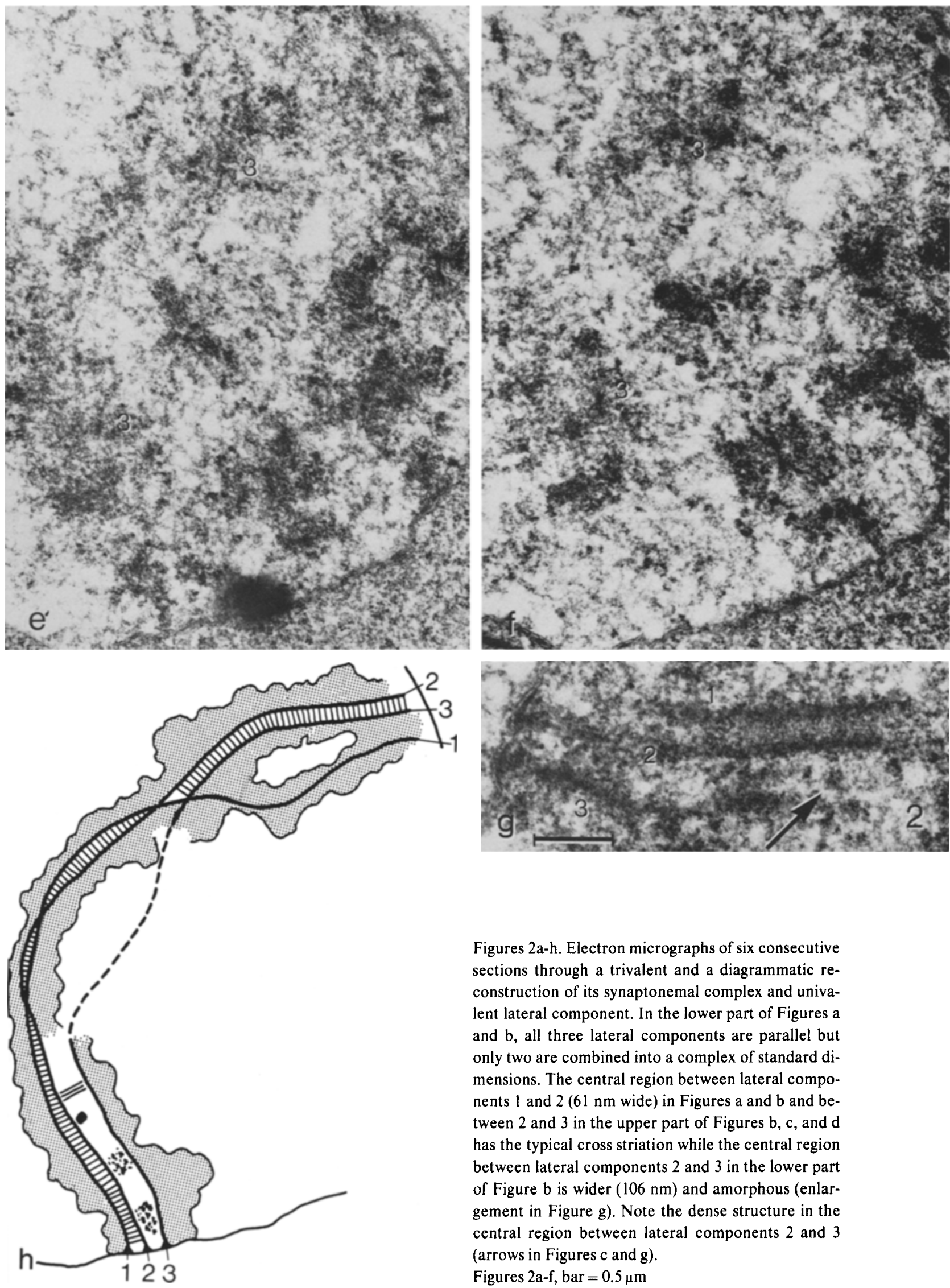

Figures 2a-h. Electron micrographs of six consecutive sections through a trivalent and a diagrammatic reconstruction of its synaptonemal complex and univalent lateral component. In the lower part of Figures a and $b$, all three lateral components are parallel but only two are combined into a complex of standard dimensions. The central region between lateral components 1 and $2(61 \mathrm{~nm}$ wide) in Figures $a$ and $b$ and between 2 and 3 in the upper part of Figures b, c, and d has the typical cross striation while the central region between lateral components 2 and 3 in the lower part of Figure $b$ is wider $(106 \mathrm{~nm})$ and amorphous (enlargement in Figure g). Note the dense structure in the central region between lateral components 2 and 3 (arrows in Figures $\mathrm{c}$ and $\mathrm{g}$ ).

Figures 2a-f, bar $=0.5 \mu \mathrm{m}$

Figure $2 \mathrm{~g}$, bar $=0.2 \mu \mathrm{m}$ 


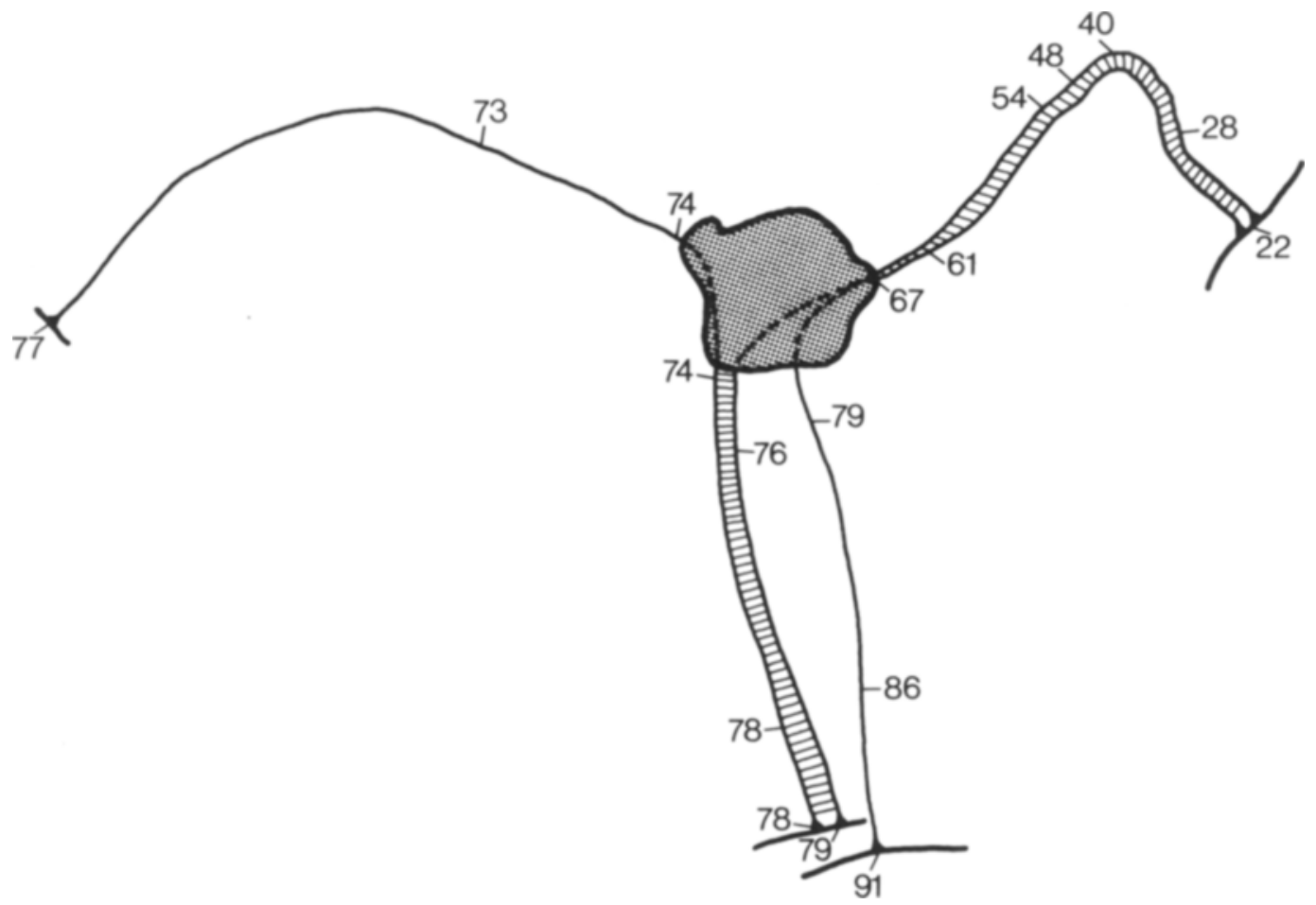

Figure.3. A reconstruction of chromosomes 1 from nucleus 4. Synaptonemal complex formation between different lateral components at either end of the three homologues has led to formation of a trivalent, the site of pairing partner exchange being inside the knob. The dashed lines inside the knob indicate that the synaptonemal complex and the lateral components are continuous through the knob but less distinct than when present in the nucleoplasm.

grossly paired set of homologues in such a way that it involves different combinations of lateral components at the two ends, a trivalent is formed (Figures 2 and 3). Twelve such cases of exchange of pairing partners resulting in formation of trivalents were found in the two reconstructed nuclei. One nucleus had 8 trivalents of 28 possibles, (Figure 1) and the other had 4, suggesting that during late zygotene the exchange of pairing partner occures exclusively between homologous chromosomes. The gross pairing was not affected by the shift of pairing partner during synaptonemal complex formation, as the segments of unpaired lateral components of a trivalent in most cases remain associated with the intimately paired stretches containing synaptonemal complexes (Figure 1).

The lengths of synaptonemal complexes and unpaired lateral components of the two reconstructed nuclei at early pachytene are given in
Table II. In those cases where the bivalent and its homologous univalent were grossly aligned along the entire distance between their attachment sites on the nuclear envelope, the ratios of synaptonemal complex lengths of the bivalents to the lateral component lengths of their homologous univalents were close to one (e.g., chromosomes 2, 6, 17, 18, 20, 26, 28 in Figure 1 and Table II). If a bivalent and its homologous univalent were only partly associated or entirely unassociated, the ratio of synaptonemal complex length to lateral component length of the three homologous chromosomes deviated significantly from one (e.g., 3, 4, 5, 8 in Figure 1 and Table II). In a few cases, the deviation of the ratio from one could be explained by a mechanical stretching of the bivalents or univalents due to entanglement with other chromosomes (e.g., chromosomes 1, 11, 22, 23 in Figure 1 and Table II). 


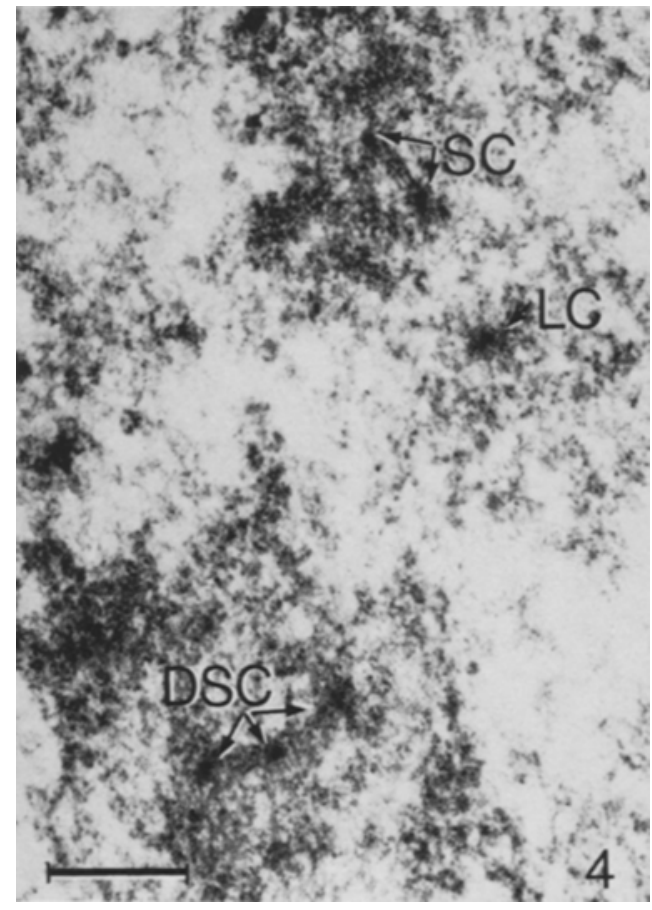

Figure 4. A cross section through two sets of three homologues. In the lower part of the micrograph, the three lateral components are connected with central region material whereas in the upper triplet, the third lateral component is located $190 \mathrm{~nm}$ from the synaptonemal complex of the bivalent. In the lower set of three homologues the left hand two lateral components are separated with a central region of $80 \mathrm{~nm}$ width whereas the third lateral component is separated with material spanning $100 \mathrm{~nm}$.

SC, synaptonemal complex. LC, lateral component. DSC, double synaptonemal complex

$\mathrm{Bar}=0.2 \mu \mathrm{m}$.

Figures 5a-c. Three consecutive sections through the lateral component attachment sites on the nuclear envelope of three homologues at early pachytene. Over a shorter stretch, all three lateral components (Figure a) have approached each other side by side with a distance of $50 \mathrm{~nm}$ between them but the central regions are amorphous without the ladderlike organization characteristic of completed synaptonemal complexes in nuclei of later stages. Note the dense structure (arrow in Figure b) in the central region of the synaptonemal complex where the third late. ral component diverges from the synaptonemal complex.

$\mathrm{Bar}=0.2 \mu \mathrm{m}$.
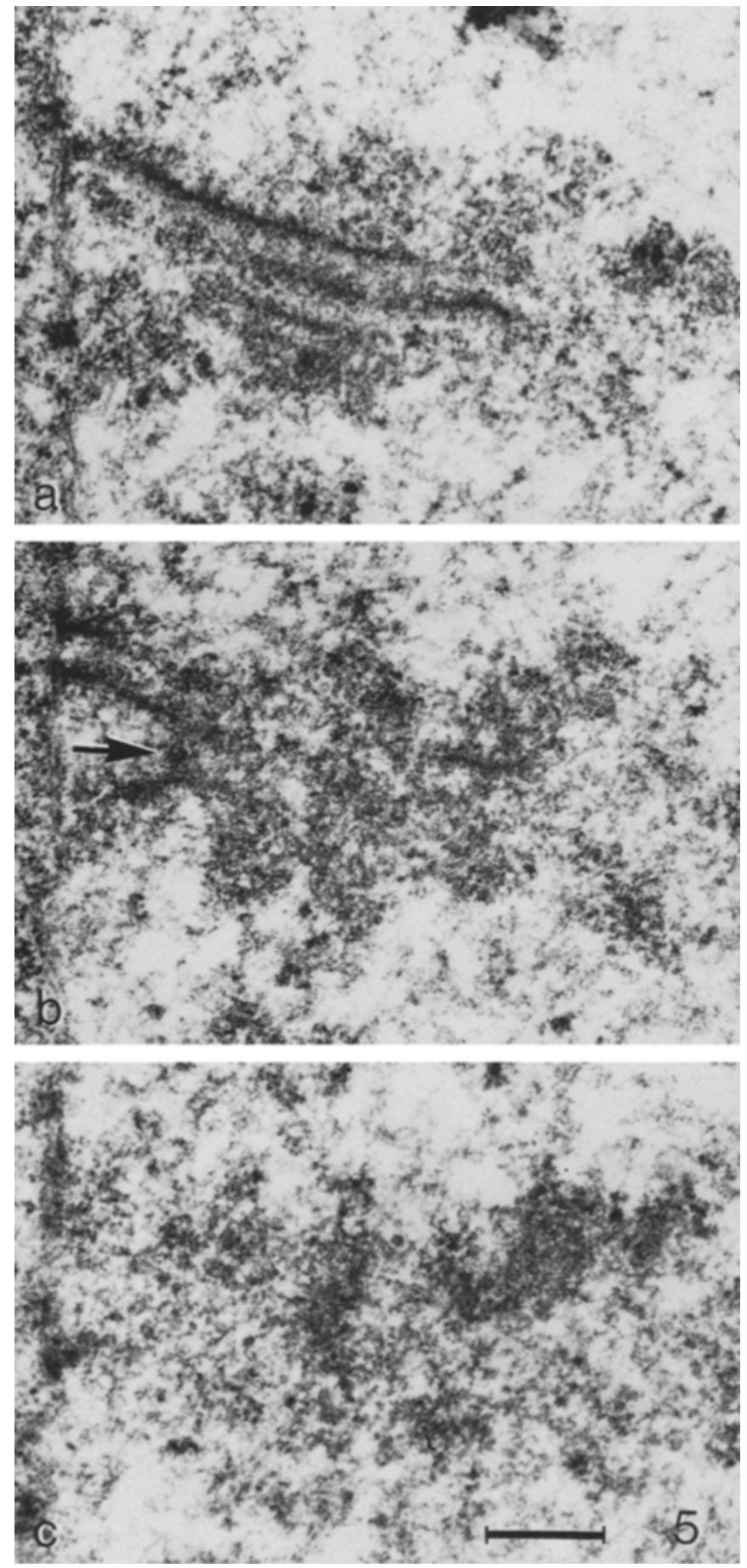


\section{S. W. RASMUSSEN: Chromosome pairing in triploid Bombyx mori}

Figures 6a-c. Reconstruction of the synaptonemal complexes and lateral components of the 84 chromosomes of an early to mid pachytene nucleus (number 3 ). This reconstruction reveals the first phase in the dispersal of the chromosome bouquet. As compared to the nucleus in Figure 1, the distance between the attachment sites of a bivalent and its third homologous univalent has increased in many cases. Three univalents, chromosomes 6 , 8 , and 12 in Figure $b$ are completely separated from their bivalents as compared to 1 in the nucleus of Figure 1 . In those cases where the three homologous telomeres are still associated on the nuclear envelope, the univalent telomere appears to have moved away from the bouquet together with the bivalent telomere (e.g., chromosomes 10, 13, 22

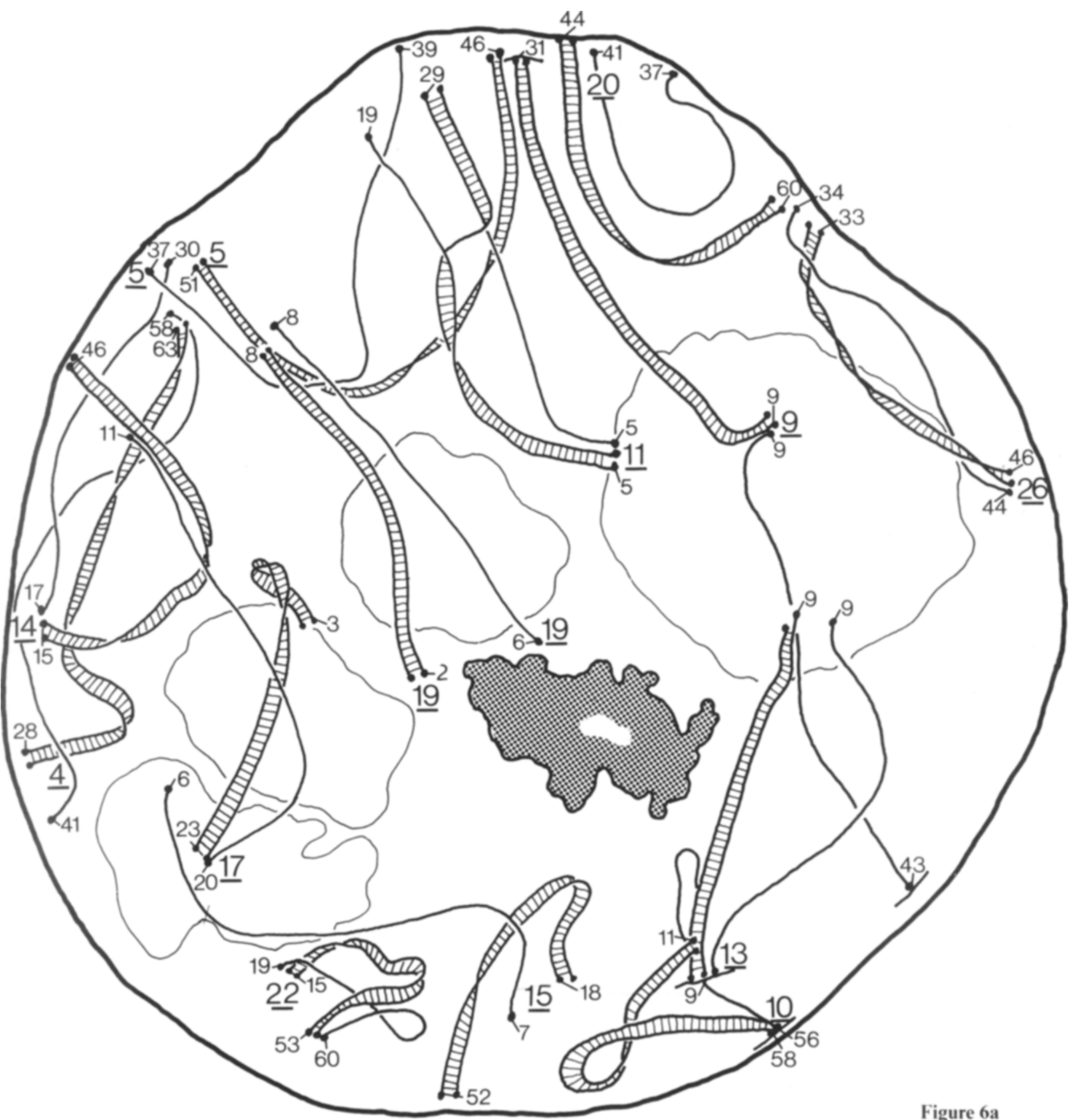


and 26 in Figure a). A total of 26 bivalents, one trivalent (number 11 in Figure a), and 24 univalents are found. The remaining 3 univalents and the two homologous chromosomes 12 are accounted for in Figure $b$ as follows: One chromosome 16 and one chromosome 23 have paired non-homologously forming a synaptonemal complex with one chromosome 12 . The other chromosome 12 has formed a synaptonemal complex with one chromosome 28 in a non-homologous association. A bivalent formation of two of the three chromosomes 12 has apparently been prevented in this nucleus by the involvment of two chromosomes in non-homologous pairing with chromosomes 16,23 , and 28 .

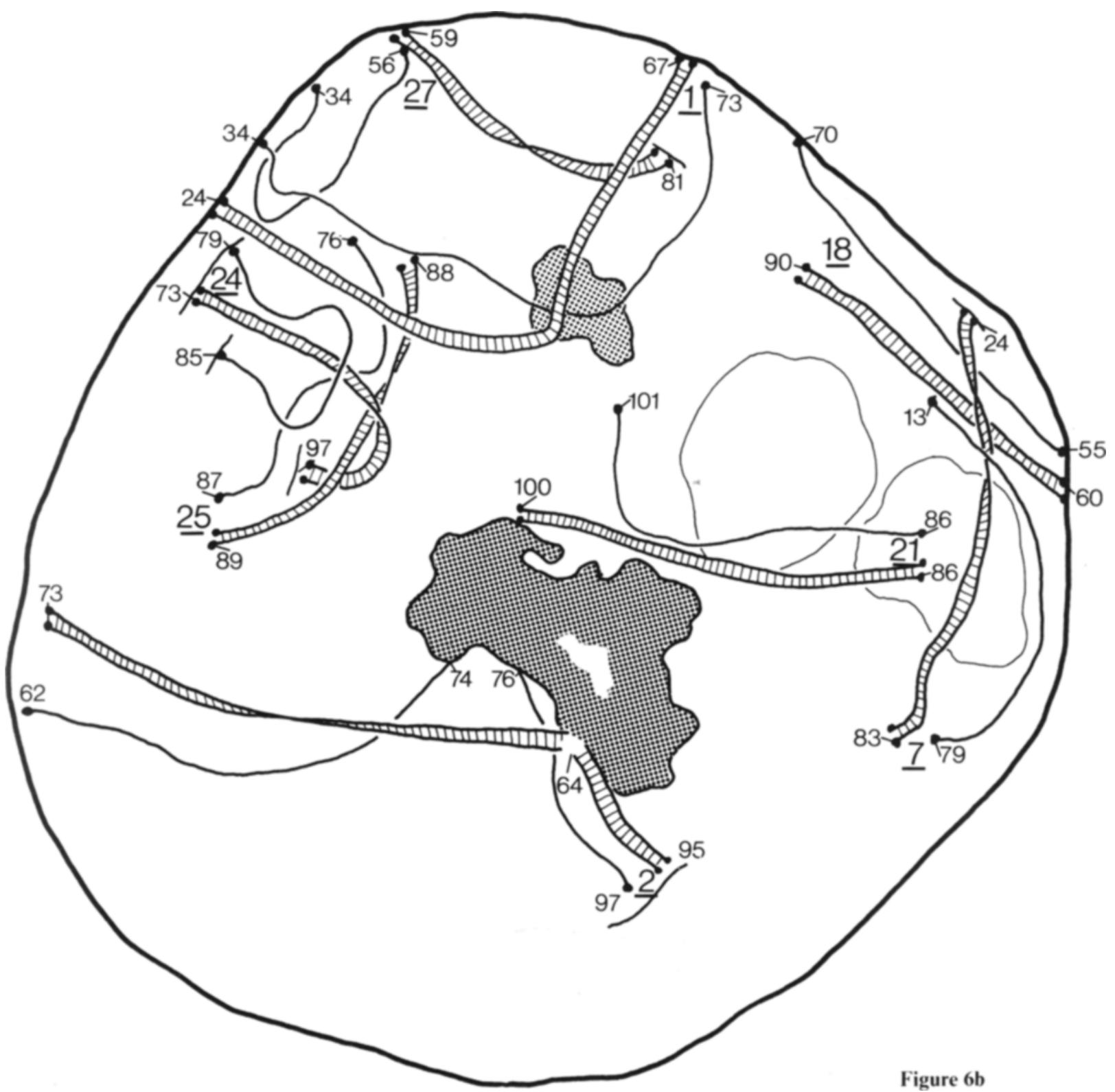




\section{S. W. RASMUSSEN: Chromosome pairing in triploid Bombyx mori}

\subsection{Early to mid pachytene (nuclei 3 and 4 )}

In two completely reconstructed nuclei for this interval, the morphological polarity of the whole cell and of the nucleus was less pronounced (Figure 6). The larger nuclear vacuoles had lost their continuity with the inner mem- brane of the nuclear envelope and the smaller vesicles in the region of chromosome attachment, which were present at the previous stage, could no longer be recognized. In both nuclei 26 bivalents with continuous synaptonemal complexes between the attachment sites on the

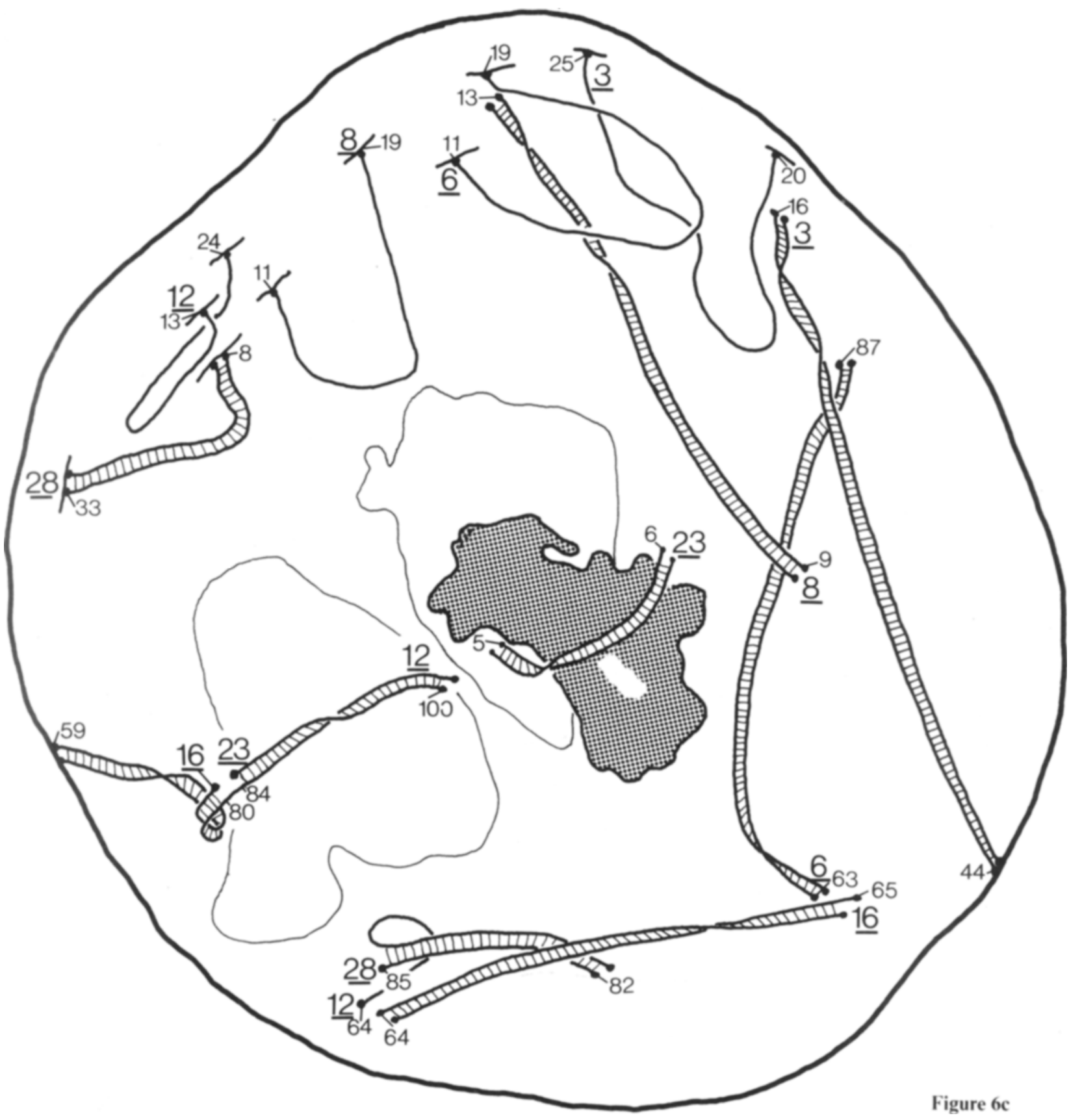


nuclear envelope were present (versus 20 and 24 in nuclei 1 and 2). There was only 1 trivalent in each nucleus as compared to 4 and 8 in the previous stage. The frequency of the close location of three homologous telomeres as well as the frequency of gross alignment between the bivalents and homologous univalents had declined. Many attachment sites of the synaptonemal complexes had moved away from the bouquet region and in some instances the univalents were left behind in the bouquet (Figures
$7 \mathrm{~b}$ and 17$)$. In other instances, especially in nucleus 3 (Figure 6 and Table I), the univalent homologue remained associated with the bivalent and was moved from the bouquet region together with the bivalent.

As mentioned, one homologous trivalent was found in each of the two nuclei, the lateral component lengths amounting to $5.3,5.1,5.9 \mu \mathrm{m}$ and $8.1,9.0,9.2 \mu \mathrm{m}$. In the latter trivalent, the chromosomes are marked by a knob and can thus be identified as the three homologues of

Table II

Length in $\mu \mathrm{m}$ of synaptonemal complexes and unpaired lateral components at early zygotene ${ }^{a)}$.

\begin{tabular}{|c|c|c|c|c|c|c|c|c|}
\hline \multicolumn{5}{|c|}{ Nucleus 1} & \multicolumn{4}{|c|}{ Nucleus 2} \\
\hline Chromosome & $\mathrm{SC}\left(\mathrm{LC}_{1}\right)$ & $\mathrm{LC}_{2}$ & $\mathrm{LC}_{3}$ & $\mathrm{SC} / \mathrm{LC}$ & $\operatorname{SC}\left(\mathrm{LC}_{1}\right)$ & $\mathrm{LC}_{2}$ & $\mathrm{LC}_{3}$ & $\mathrm{SC} / \mathrm{LC}$ \\
\hline 1 & $6.1 \mathrm{b)}$ & 6.7 & 7.6 & 0.8 & $7.2 \mathrm{~b})$ & 7.8 & 7.2 & 0.9 \\
\hline 2 & 6.3 & 5.9 & & 1.1 & $5.5^{b)}$ & 6.1 & 5.7 & 0.9 \\
\hline 3 & 6.5 & 4.9 & & 1.3 & $5.9^{c)}$ & 5.3 & & 1.1 \\
\hline 4 & 6.2 & 4.3 & & 1.4 & $5.8^{c)}$ & 3.6 & & 1.6 \\
\hline 5 & $6.1 \mathrm{b)}$ & 6.2 & 5.2 & 1.2 & $5.9 \mathrm{~b})$ & 5.6 & 5.7 & 1.0 \\
\hline 6 & $5.9^{\text {b) }}$ & 6.3 & 5.8 & 0.9 & $5.6^{\mathrm{b})}$ & 5.0 & 5.5 & 1.1 \\
\hline 7 & 5.3 & 4.8 & & 1.1 & 5.2 & 5.2 & & 1.0 \\
\hline 8 & $5.0 \mathrm{c})$ & 3.6 & & 1.4 & 5.1 & 4.7 & & 1.1 \\
\hline 9 & 5.0 & 4.5 & & 1.1 & $5.1^{\mathrm{b})}$ & 5.1 & 5.0 & 1.0 \\
\hline 10 & 5.0 & 4.9 & & 1.0 & 4.9 & 5.0 & & 1.0 \\
\hline 11 & 4.8 & 5.3 & & 0.9 & 4.8 & 4.4 & & 1.1 \\
\hline 12 & 4.8 & 4.8 & & 1.0 & 4.6 & 4.7 & & 1.0 \\
\hline 13 & 4.7 & 4.0 & & 1.2 & 4.5 & 4.4 & & 1.0 \\
\hline 14 & 4.6 & 4.0 & & 1.2 & 4.5 & 4.0 & & 1.1 \\
\hline 15 & 4.6 & 4.5 & & 1.0 & 4.4 & 4.1 & & 1.1 \\
\hline 16 & $4.6^{b)}$ & 4.6 & 4.5 & 1.0 & 4.4 & 4.0 & & 1.1 \\
\hline 17 & 4.4 & 4.4 & & 0.9 & 4.3 & 4.0 & & 1.1 \\
\hline 18 & 4.3 & 4.0 & & 1.1 & 4.2 & 4.4 & & 1.0 \\
\hline 19 & 4.2 & 3.6 & & 1.2 & $4.2^{b)}$ & 4.1 & 4.4 & 0.9 \\
\hline 20 & 4.1 & 4.3 & & 0.9 & 4.1 & 4.2 & & 1.0 \\
\hline 21 & 3.9 & 3.5 & & 1.1 & $4.2^{b)}$ & 4.0 & 3.8 & 0.9 \\
\hline 22 & 3.9 & 4.4 & & 0.9 & 3.9 & 3.0 & & 1.3 \\
\hline 23 & 3.8 & 3.2 & & 1.2 & $3.9 \mathrm{~b})$ & 3.8 & 3.6 & 1.1 \\
\hline 24 & 3.7 & 3.4 & & 1.1 & 3.5 & 3.5 & & 1.0 \\
\hline 25 & 3.7 & 3.6 & & 1.0 & 3.5 & 3.5 & & 1.0 \\
\hline 26 & 3.7 & 3.8 & & 1.0 & 3.3 & 3.9 & & 0.9 \\
\hline 27 & 3.6 & 3.5 & & 1.0 & 3.2 & 2.9 & & 1.1 \\
\hline 28 & 3.4 & 3.5 & & 1.0 & 2.8 & 2.9 & & 1.0 \\
\hline
\end{tabular}

a) the chromosomes are arranged according to length of the bivalent (average of the three lateral components is used for the trivalents).

b) trivalent (the lengths of the lateral components are given). The $\mathrm{SC} / \mathrm{LC}$ ratio is calculated using the average of the two lateral components closest in length as the $\mathrm{SC}$ length.

c) bivalent and univalent not associated on the nuclear envelope. 
chromosome 1 (Figure 4). Five cases of nonhomologous pairing were revealed in the two nuclei; one hairpin, two non-homologous associations of two chromosomes, and two nonhomologous associations of three chromosomes (Table IV). The non-homologously paired chromosomes were all attached to the nuclear envelope outside the bouquet region. The la- teral component lengths of the two configurations involving three non-homologously associated chromosomes in nuclei 3 and 4 are $3.8,6.6$, $2.8 \mu \mathrm{m}$ and 5.3, 5.0, $6.2 \mu \mathrm{m}$. Two of the chromosomes of the latter association could be homologous as judged by the similarity in lengths of the lateral components.

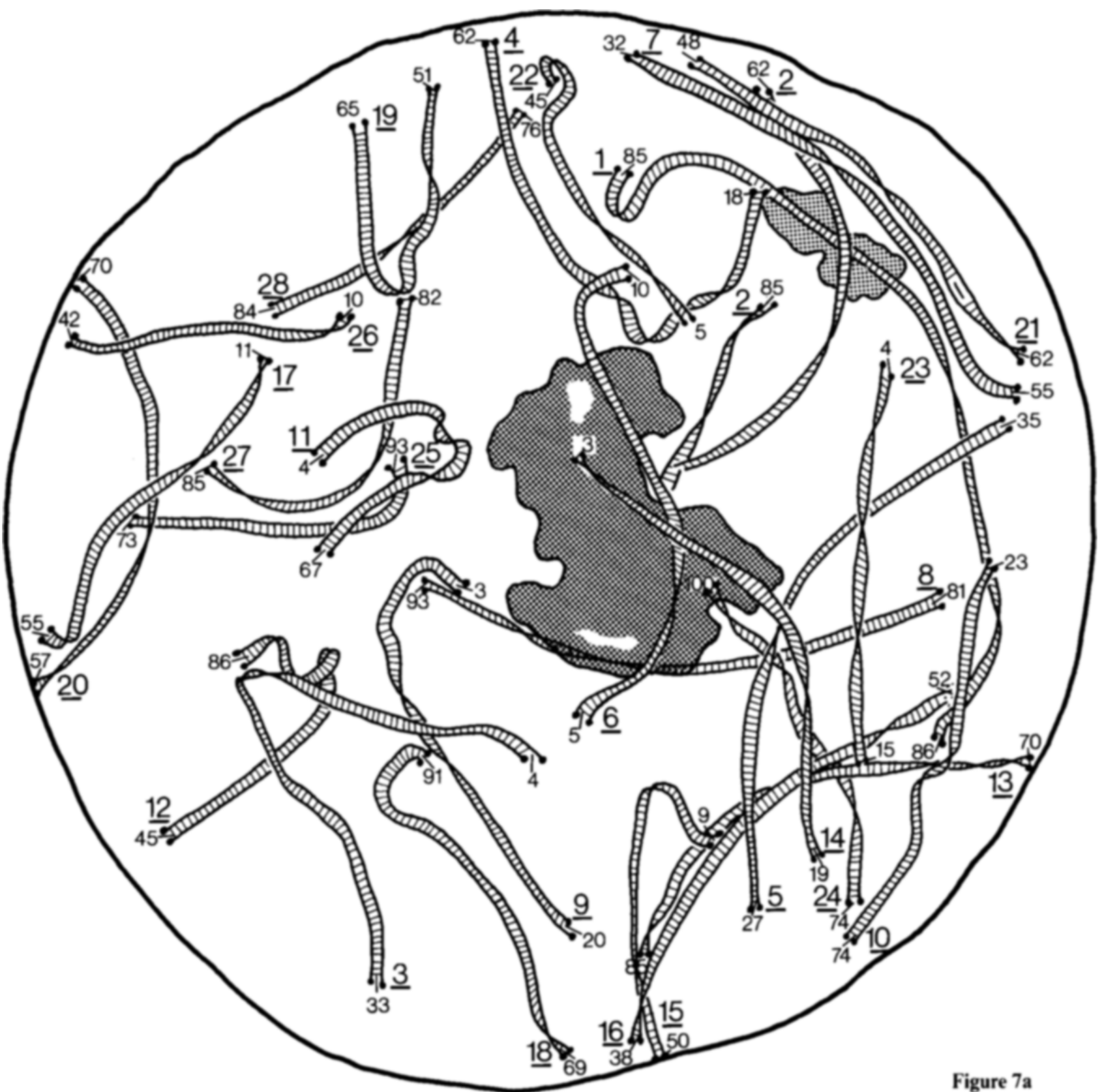




\section{S. W. RASMUSSEN: Chromosome pairing in triploid Bombyx mori}

Figures $7 \mathrm{a}$ and $\mathrm{b}$. A reconstruction of a mid pachytene nucleus (number 5). Figure a shows the complete diploid complement of 28 bivalents each with a synaptonemal complex spanning their entire length. The bivalents are distributed uniformly in the nucleus in contrast to the univalents in Figure b. The attachment sites of the univalents are still concentrated in one half of the nucleus (the left part in Figure b). The univalents which are not attached to the nuclear envelope with both telomeres in the bouquet region of the nuclear envelope are frequently stretched out (chromosomes 1, 6, 8, and 9) whereas those attached in the bouquet region are recognized by their loop organization. Univalent 23 with a short piece of synaptonemal complex in a foldback paired interstitial segment represents the only example among the 11 reconstructed muclei of synaptonemal complex formation not initiated at the nuclear envelope.

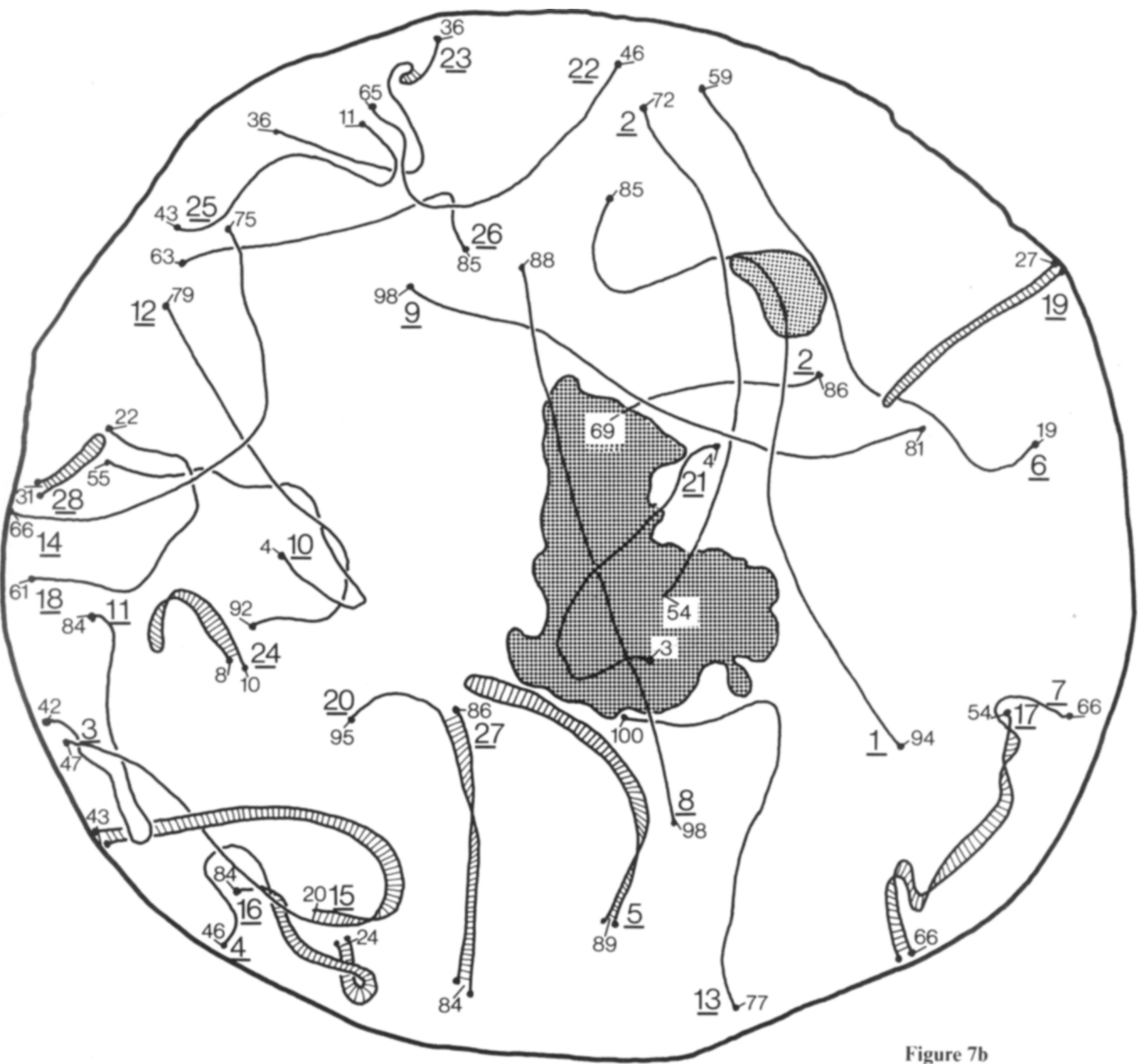




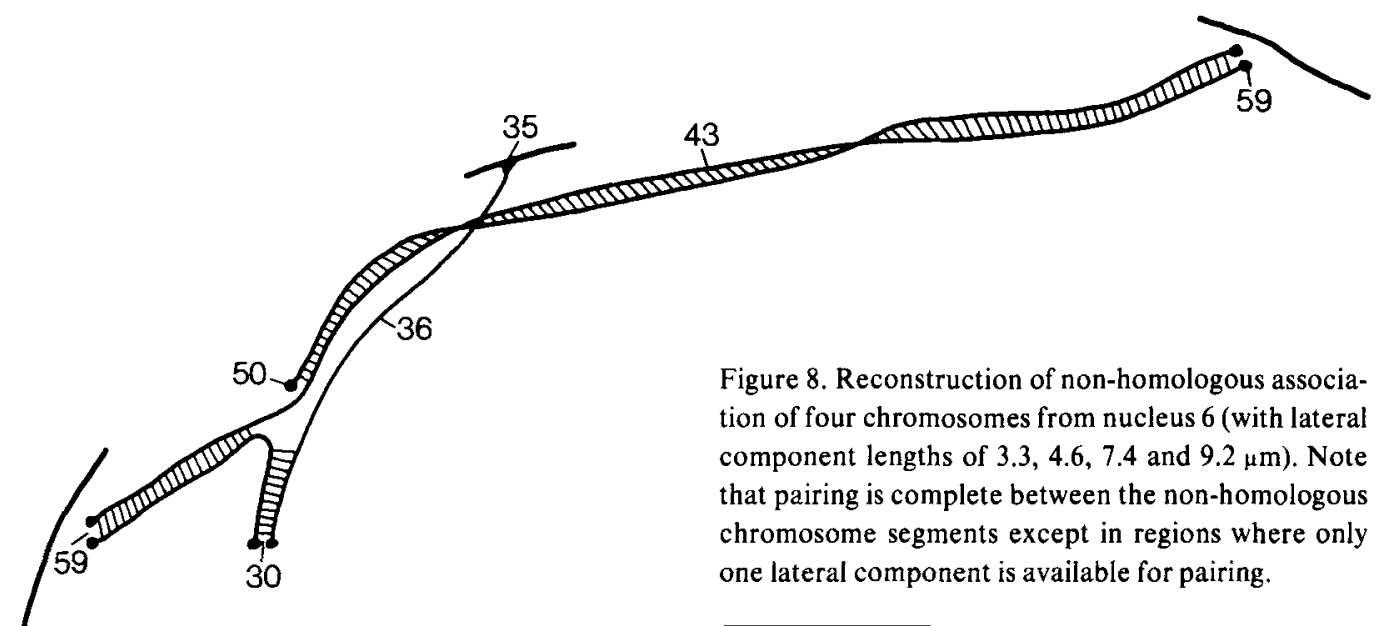

\subsection{Mid to late pachytene (nuclei 5-11)}

At this stage, nuclear vacuoles were no longer present. The cytoplasmic organelles were uniformly distributed in the cell and the nuclear polarity observed earlier was almost absent. The majority of the bivalents and the nonhomologously paired chromosomes had detached from the nuclear envelope and were free in the nucleoplasm.

Trivalents were not found in the seven reconstructed nuclei (numbers 5-11, see Figures 7 and 13 and Table IV). Instead various nonhomologous chromosome associations were observed. Four of the nuclei were triploid with 84 chromosomes and three nuclei were hypertriploid with 87 chromosomes (Table IV). Between 25 and 28 bivalents (i.e., maximal number possible) were present in the triploid oocytes, whereas 23,28 , and 30 bivalents were counted in the nuclei with 87 chromosomes.

The number of univalents varied between 18 and 27 in the triploid nuclei. There were 18 or 19 in the nuclei with 87 chromosomes. A number of univalents, $0-4$ per nucleus, form hairpins that are paired with a synaptonemal complex by folding back on themselves. Between 2 and 9 associations of two to four non-homologous chromosomes were found per nucleus (Table IV). Examples for these are depicted in Figures $8-12,14$, and 15 . In Figure $7 \mathrm{~b}$ and $13 \mathrm{~b}$, the two lateral components of non-homologous bivalents are of different length, and demonstrate that the pairing of non-homologous lateral com- ponents into synaptonemal complexes does not involve an "adjustment" of lateral component length. Even relatively small differences in length between the two lateral components were reflected by an unpaired segment of lateral component extending beyond the completed synaptonemal complex. It was characteristic of "hairpins" (foldback pairing of a single chromosome) and all other non-homologous associations, that the synaptonemal complexes were continuous from the attach-

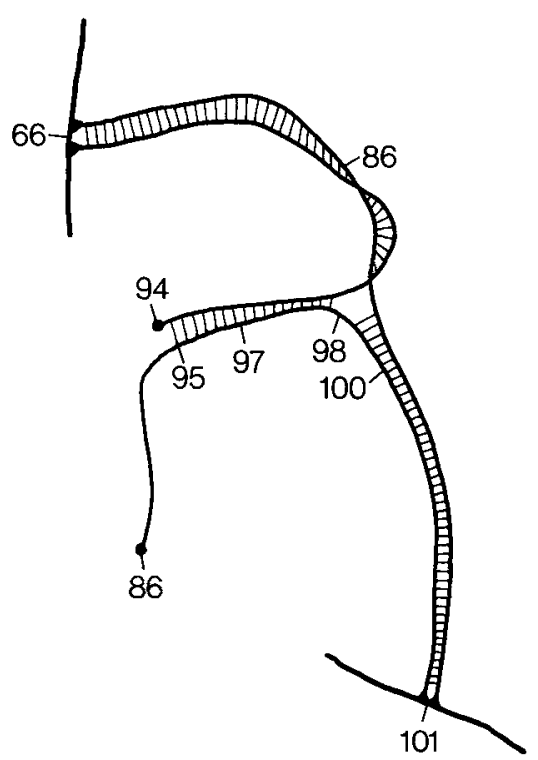

Figure 9. Reconstruction of a non-homologous association of three chromosomes (with lateral component lengths of $5.3,5.0$, and $6.2 \mu \mathrm{m}$ ) from nucleus 4 . 
ment sites on the nuclear envelope to a site of lateral component exchange or to the site of termination of one of the two lateral components of the complex (Figures 8-12). It is likely that synaptonemal complex formation is initiated at the attachment site on the nuclear envelope. In contrast to pairing in trivalents involving only 2 of the 3 lateral components (Figures 2 and 3), the formation of synaptonemal complexes in the non-homologous associations was as complete as possible be-

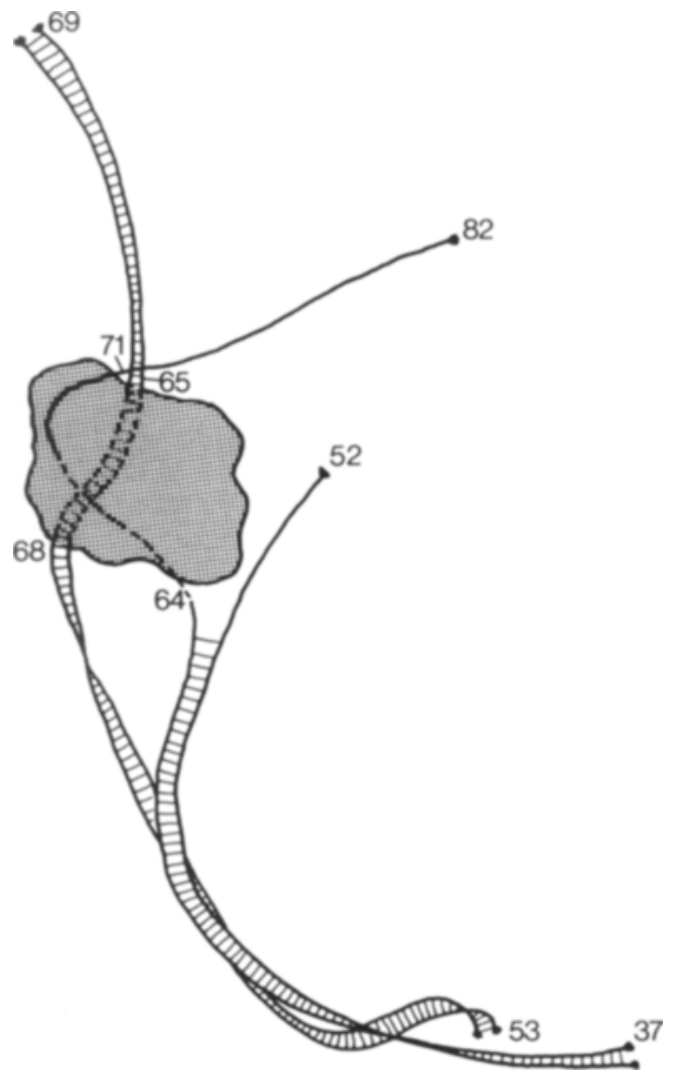

Figure 11. Reconstruction of an association of one of the chromosomes 1 with a non-homologous chromosome in nucleus 7 . The lengths of the synaptonemal complex and the third lateral component of chromosome 1 are 8.5 and $10.1 \mu \mathrm{m}$ respectively and the lateral component length of the non-homologously paired chromosome is $6.9 \mu \mathrm{m}$. The dashed lines inside the knob indicate that the synaptonemal complex and the lateral component are continuous through the knob although the morphology of the components is less distinct.

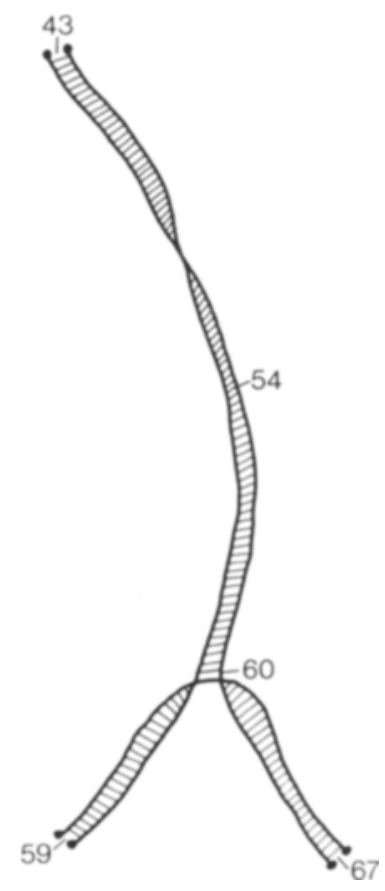

Figure 10. Reconstruction of synaptonemal complex association formed by three chromosomes in nucleus 9. The similarity in lateral component lengths of the two longer chromosomes $(6.7,6.9$, and $3.3 \mu \mathrm{m})$ indicates that they are homologous.

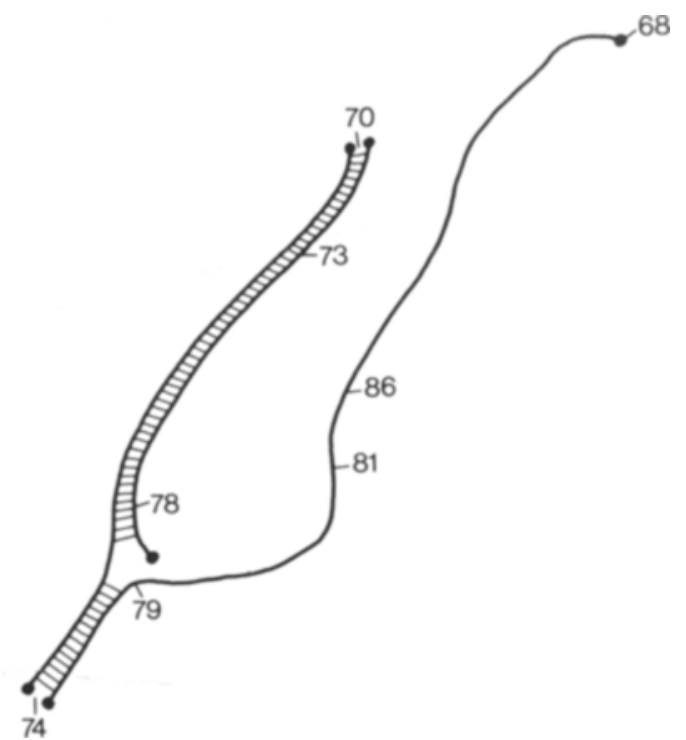

Figure 12. Reconstruction of a non-homologous pairing of three chromosomes (with lateral component lengths of $3.8,5.0$, and $7.9 \mu \mathrm{m}$ ) in nucleus 7 . Note the completeness of the non-homologous pairing. 
tween all three lateral components; unpaired stretches of lateral component being in most cases limited to regions where no pairing partner was available. It cannot be excluded that the associations of 3 chromosomes depicted in Figures 10,14, and 15 consist of two homologous chromosomes and one non-homologous. It is possible that these non-homologous associations have occured during the correction of pairing in a trivalent at early pachytene, as a result of a competition between the two homologues and a non-homologous third chromosome. From Figures $17 \mathrm{a}-\mathrm{c}$ and Table $\mathrm{I}$ it is apparent that the lateral components of univalents have a tendency to remain attached to the nuclear envelope within the bouquet region longer than those of the bivalents.

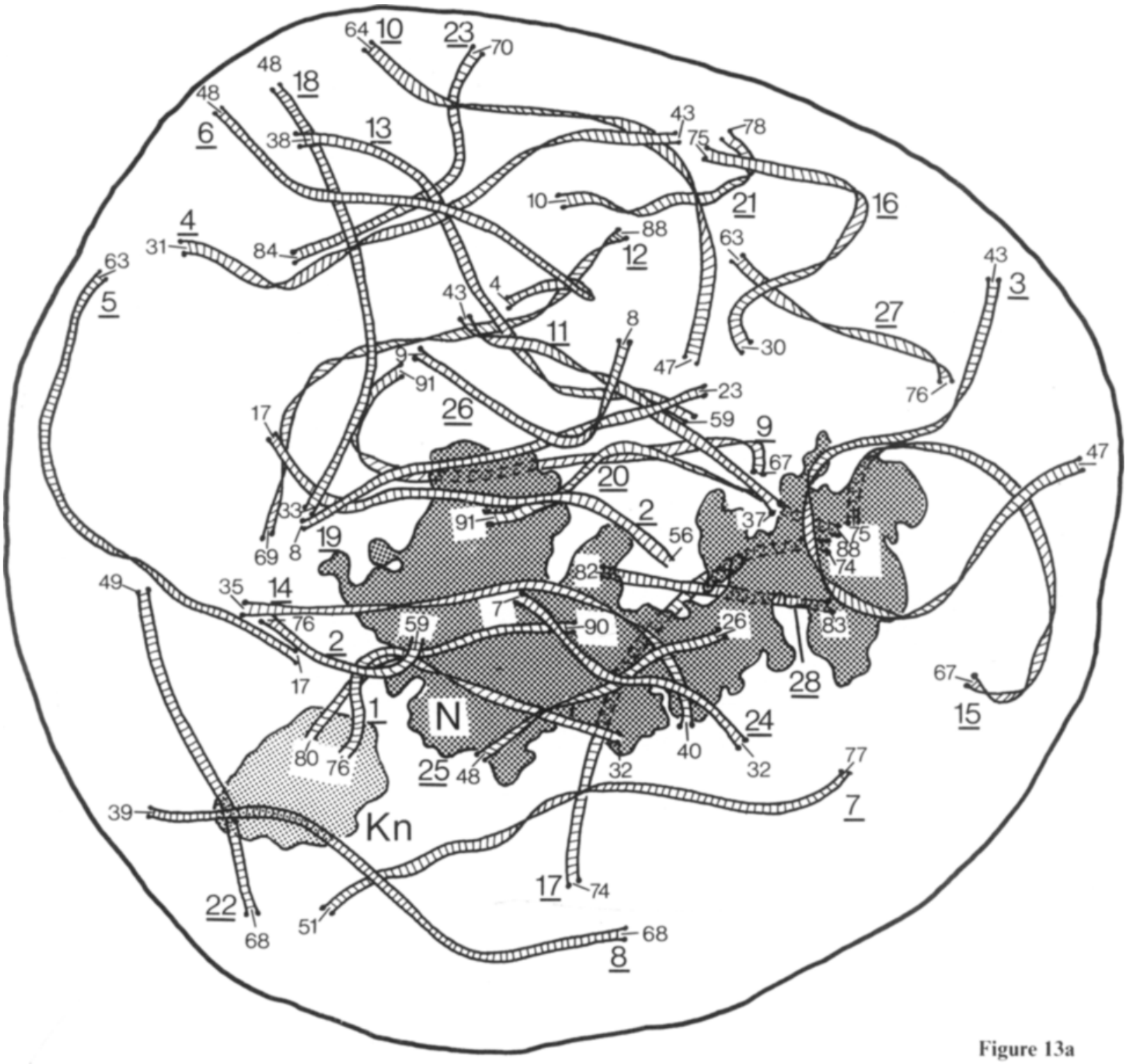


Figures $13 \mathrm{a}$ and $\mathrm{b}$. A reconstruction of the synaptonemal complexes and lateral components of the 87 chromosomes from a late pachytene nucleus (number 11). Figure a shows 28 bivalents each with a synaptonemal complex from end to end. The bivalents are no longer attached to the nuclear envelope and are evenly distributed throughout the nucleus. The univalents, hairpins (chromosomes 29 and 31 ), the associations of two non-homologously paired chromosomes $(5+13,6+19,1+26,4+15$ and $9+27)$, and the non-homologous association of three chromosomes $(3+7+8)$ have also become detached from the nuclear envelope and are dispersed throughout the nucleus (Figure b). Three dense nodules are present in Figure b; one is associated with a lateral component of the non-homologous synaptonemal complex formed by chromosomes 4 and 15 , the second with the lateral component of chromosome 11 , and the third one is lying close to the lateral component of the univalent chromosome 16. In all the non-homologously paired chromosomes, unpaired lateral components stretches are found only where no pairing partner is available (e.g., $3+7+8,5+13,6+19$, and $4+15$ in Figure b).

$\mathrm{N}$, nucleolus. Kn, knob.

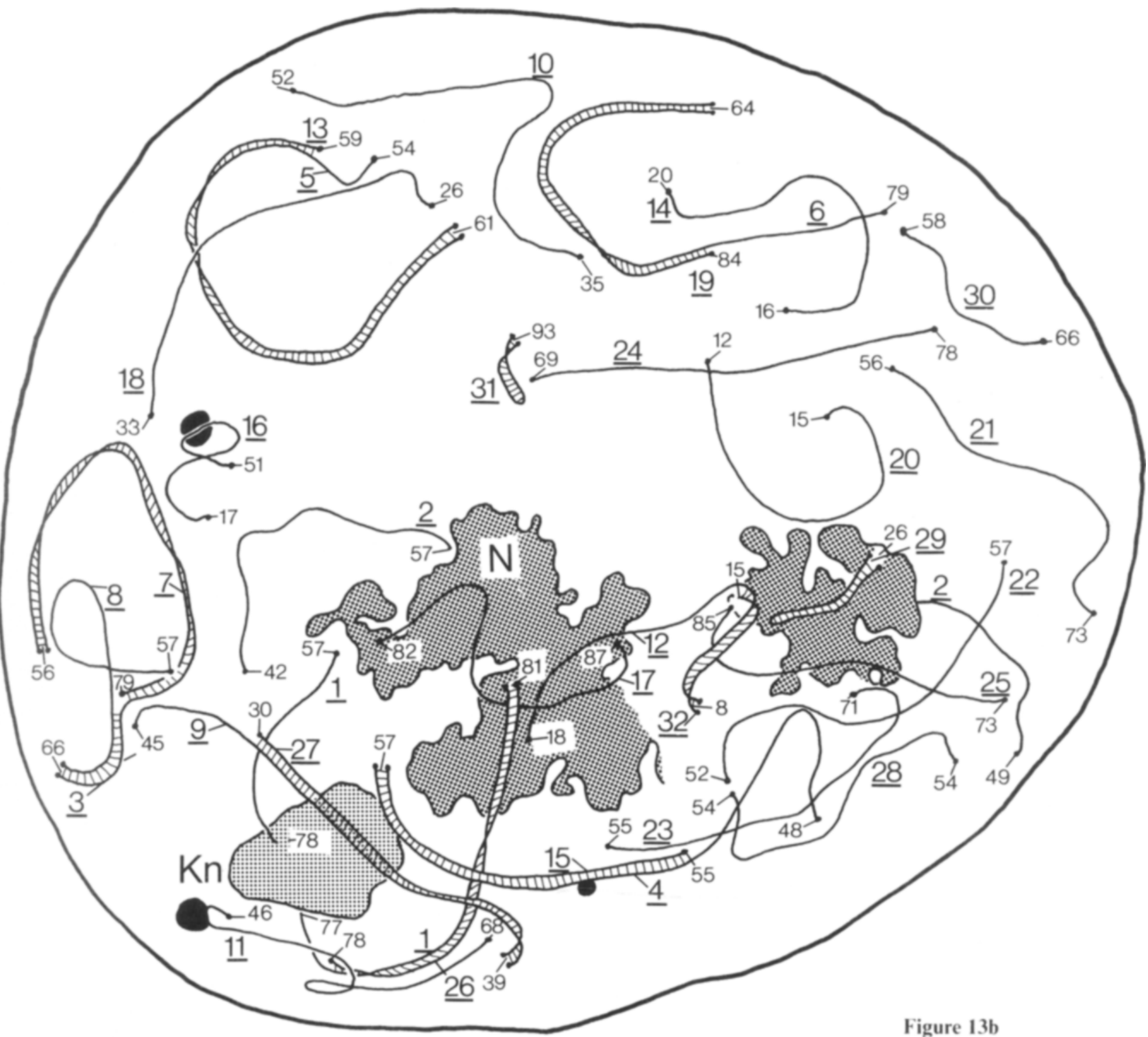

Carlsberg Res. Commun. Vol. 42, p. 163-197, 1977 


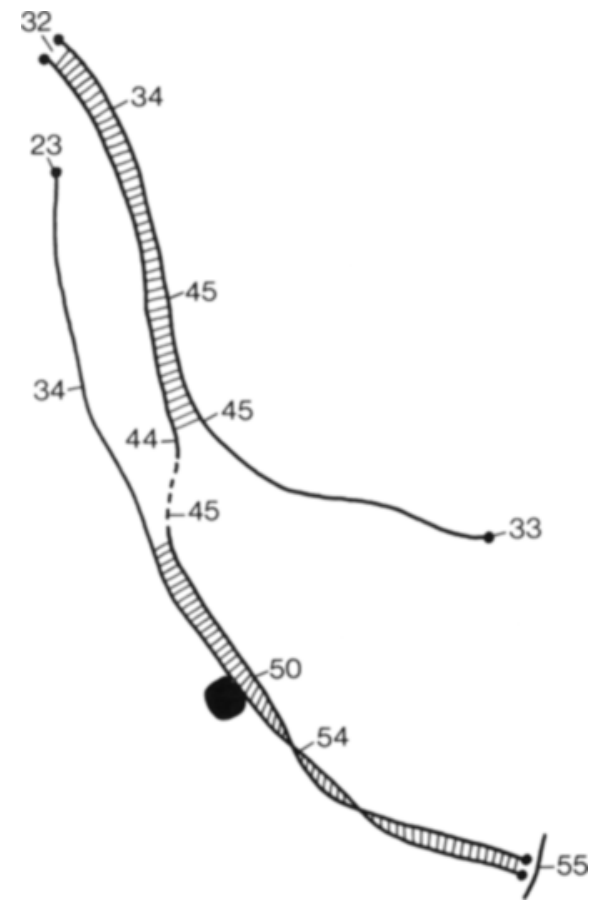

Figure 14. Reconstruction of an association of three chromosomes in nucleus 9 . The similarity in lengths of two of the lateral components ( 7.1 and 7.8 versus $5.7 \mu \mathrm{m}$ for the third) indicates that two of the three lateral components might be homologous. This association constitutes one of the few examples of incomplete non-homologous pairing (compare with Figures $9,10,11$, and 12 ).

Two to ten nodules with a diameter of approximately 200-300 nm and with an electron density slightly lower than that of the nucleoli were found in four nuclei at mid pachytene and in one at late pachytene (nuclei 6-9 and 11, respectively) (Figures 13b, 14, 15 and 16). The nodules were associated either with homologous or non-homologous synaptonemal complexes, or with unpaired lateral components. Some were also located free in the nucleoplasm. It is not clear whether these nodules are involved in crossing over as suggested by CARPENTER (3) for similar structures in Drosophila. If they are, then the lack of crossing over in Bombyx females has to be the result of their malfunction or a block at some other point in the sequence of events leading to crossing over. It should be noted that nodules - when present at all - were observed associated with synaptonemal complexes only in 2-6 instances per nucleus and with lateral components at 1 or 2 sites per nucleus (Table III). The nodules were most frequent in nucleus 7 and as nuclei 6-9 appeared to be in a similar stage of development, the presence of the nodules presumably was restricted to a short interval of the pachytene stage. This may explain why these nodules were not seen in diploid pachytene nuclei (28).

As mentioned, the total number of chromosomes in two of the five mid pachytene nuclei (numbers 8 and 9) and in one of the two nuclei at late pachytene (number 11) was 87 (Table IV). Nuclei 6,7 and 8 belonged to the same 8 -cell cluster, whereas nucleus 9 was from the same individual but from a different cluster. Nuclei 10 and 11 were from the same cluster. Nuclei with 87 chromosomes were thus found in three separate cell clusters in two individuals.

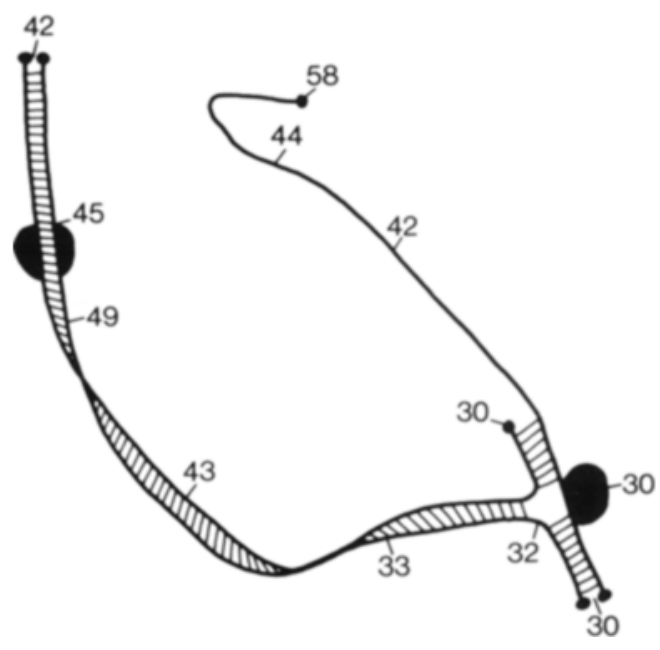

Figure 15. Reconstruction of an association of three paired chromosomes in nucleus 7 . The lengths of the lateral components $(7.6,7.5$, and $6.2 \mu \mathrm{m})$ indicate that two of the involved chromosomes are homologous. Note the dense nodule attached to homologously paired as well as to unpaired lateral components. 
Table III

Chromosome associated nodules in pachytene oocyte nuclei.

\begin{tabular}{c|c|c}
\hline $\begin{array}{c}\text { Nucleus } \\
\text { number }\end{array}$ & $\begin{array}{c}\text { Nodule associated } \\
\text { with LC of univalent }\end{array}$ & $\begin{array}{c}\text { Nodule associated } \\
\text { with LC of bivalent }\end{array}$ \\
\hline 1 & 0 & 0 \\
2 & 0 & 0 \\
3 & 0 & 0 \\
4 & 0 & 0 \\
5 & 0 & 0 \\
6 & 2 & 0 \\
7 & 1 & 6 \\
8 & 0 & 3 \\
9 & 0 & 2 \\
10 & 0 & 0 \\
11 & 1 & 0 \\
\hline
\end{tabular}

Two of these clusters also contained nuclei with 84 chromosomes, the expected number for a triploid Bombyx. In addition, some of the nuclei analyzed contained between 1 and 3 chromosome fragments less than $2 \mu \mathrm{m}$ long, (i.e., shorter than chromosome 28) with lateral components. In nucleous 8 , one of the fragments was paired into a normal-looking synaptonemal complex with the lateral components of chromosome 2 . The supernumerary chromosomes presumably are the result of a failure of sister chromatid separation in one of the preceeding mitoses, whereas the fragments possibly result from chromosome breakage. As Bombyx has holocentric chromosomes (26), such fragments can be transmitted through several generations.

\subsection{Quantitative aspects of chromosome pairing}

From the data given in Table $\mathrm{V}$ and $\mathrm{Va}$ it appears that approximately two-thirds of the lateral component length $(68 \%)$ was paired into synaptonemal complexes at the end of zygotene as would be expected if lateral components were homologously paired two-by-two, leaving the third set of chromosomes and chromosome segments unpaired. The total complex length at the beginning of pachytene (nuclei $1,2,3$ ) was

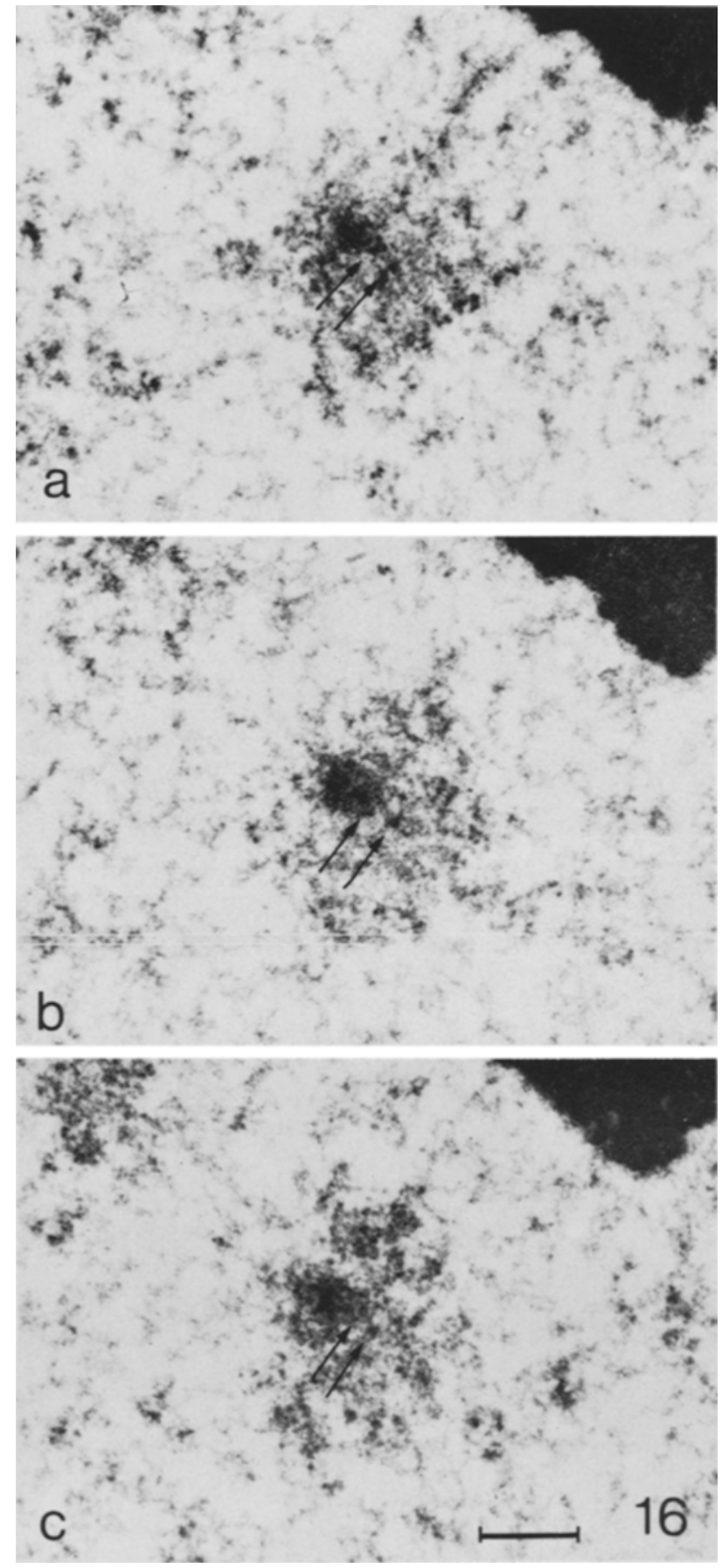

Figure 16a-c. Three consecutive sections through a dense nodule that is attached to one lateral component of a synaptonemal complex in a bivalent. The diameter of the nodule is approximately $300 \mathrm{~nm}$. The arrows indicate the synaptonemal complex in cross section. $B a r=0.5 \mu \mathrm{m}$. 
Table IV

Chromosome configurations in triploid pachytene nuclei of Bombyx mori.

\begin{tabular}{|c|c|c|c|c|c|c|c|c|c|}
\hline \multirow{2}{*}{$\begin{array}{l}\text { Nuc- } \\
\text { leus }\end{array}$} & \multirow{2}{*}{$\begin{array}{c}\text { Univa- } \\
\text { lents }\end{array}$} & \multirow{2}{*}{$\begin{array}{l}\text { Biva- } \\
\text { lents }\end{array}$} & \multirow{2}{*}{$\begin{array}{l}\text { Triva- } \\
\text { lents }\end{array}$} & \multirow{2}{*}{$\begin{array}{l}\text { Hair- } \\
\text { pins }\end{array}$} & \multicolumn{3}{|c|}{ Non-homologous pairing involving: } & \multirow{2}{*}{$\begin{array}{l}\text { Frag- } \\
\text { ments }\end{array}$} & \multirow{2}{*}{$\begin{array}{c}\text { Total } \\
\text { chromosome } \\
\text { number }\end{array}$} \\
\hline & & & & & $\begin{array}{l}2 \text { chromo- } \\
\text { somes }\end{array}$ & $\begin{array}{l}3 \text { chromo- } \\
\text { somes }\end{array}$ & $\begin{array}{l}4 \text { chromo- } \\
\text { somes }\end{array}$ & & \\
\hline 1 & 24 & 24 & 4 & 0 & 0 & 0 & 0 & 2 & 84 \\
\hline 2 & 20 & 20 & 8 & 0 & 0 & 0 & 0 & 0 & 84 \\
\hline 3 & 24 & 26 & 1 & 0 & 1 & 1 & 0 & 0 & 84 \\
\hline 4 & 23 & 26 & 1 & 1 & 1 & 1 & 0 & 0 & 84 \\
\hline 5 & 16 & 28 & 0 & 4 & 4 & 0 & 0 & 0 & 84 \\
\hline 6 & 25 & 25 & 0 & 2 & 0 & 1 & 1 & 0 & 84 \\
\hline 7 & 16 & 27 & 0 & 2 & 3 & 2 & 0 & 0 & 84 \\
\hline 8 & 19 & 30 & 0 & 0 & 4 & 0 & 0 & 3 & 87 \\
\hline 9 & 18 & 23 & 0 & 0 & 5 & 3 & 1 & 1 & 87 \\
\hline 10 & 20 & 26 & 0 & 1 & 2 & 1 & 1 & 0 & 84 \\
\hline 11 & 16 & 28 & 0 & 2 & 5 & 1 & 0 & 1 & 87 \\
\hline
\end{tabular}

a) fragtments are not included.

Tabie V

Variation in length in $\mu \mathrm{m}$ of synaptonemal complexes and lateral components during pachytene in Bombyx mori.

\begin{tabular}{c|c|c|c|c|c|c|c|c}
\hline $\begin{array}{c}\text { Nucleus } \\
\text { number }\end{array}$ & $\begin{array}{c}\text { SC length } \\
\text { of } \\
\text { bivalents }\end{array}$ & $\begin{array}{c}\text { LC length } \\
\text { of } \\
\text { univalents }\end{array}$ & $\begin{array}{c}\text { SC length } \\
\text { of } \\
\text { trivalents }\end{array}$ & $\begin{array}{c}\text { SC length of } \\
\text { non-homologous } \\
\text { associations }\end{array}$ & $\begin{array}{c}\text { LC length } \\
\text { of aberant } \\
\text { associations }\end{array}$ & $\begin{array}{c}\text { LC } \\
\text { length } \\
\text { total }\end{array}$ & $\begin{array}{c}\text { SC } \\
\text { length } \\
\text { total }\end{array}$ & $\begin{array}{c}\text { Per cent } \\
\text { LC paired } \\
\text { into SC }\end{array}$ \\
\hline 1 & 110 & 101 & 24 & 0 & 71 & 391 & 134 & 68 \\
2 & 87 & 82 & 42 & 0 & 125 & 381 & 129 & 68 \\
\hline 3 & 116 & 131 & 5 & 10 & 37 & 401 & 131 & 65 \\
4 & 143 & 127 & 8 & 15 & 58 & 470 & 166 & 70 \\
\hline 5 & 175 & 100 & 0 & 31 & 72 & 519 & 205 & 79 \\
\hline 6 & 175 & 171 & 0 & 21 & 49 & 569 & 196 & 69 \\
7 & 157 & 82 & 0 & 34 & 91 & 487 & 190 & 78 \\
9 & 166 & 114 & 0 & 20 & 41 & 488 & 186 & 76 \\
\hline 10 & 140 & 113 & 0 & 50 & 122 & 515 & 190 & 74 \\
\hline 11 & 159 & 124 & 0 & 23 & 56 & 498 & 182 & 73 \\
\hline
\end{tabular}

$131 \mu \mathrm{m}$. (The short stretches of the second complex present in the "double complexes" were not included in the total synaptonemal complex length.) In nucleus, 4 the percentage of lateral components which is paired into synaptonemal complexes had increased to $70 \%$ of the total lateral component length. Simultaneously, the length of synaptonemal complexes between 
non-homologous chromosome segments increased to $15 \mu \mathrm{m}$. In the remaining 7 nuclei, the percentage of lateral components paired into synaptonemal complexes (homologously and non-homologously) amounted to $76 \%$ the lowest value being $69 \%$ and the greatest $80 \%$. The increase in synaptonemal complex length from $131 \mu \mathrm{m}$ (average of nuclei 1-3) to an average of $194 \mu \mathrm{m}$ can be accounted for entirely bythe increase in length of synaptonemal complexes between non-homologous chromosome segments.

It thus appears that chromosome pairing with the synaptonemal complex in triploid Bombyx

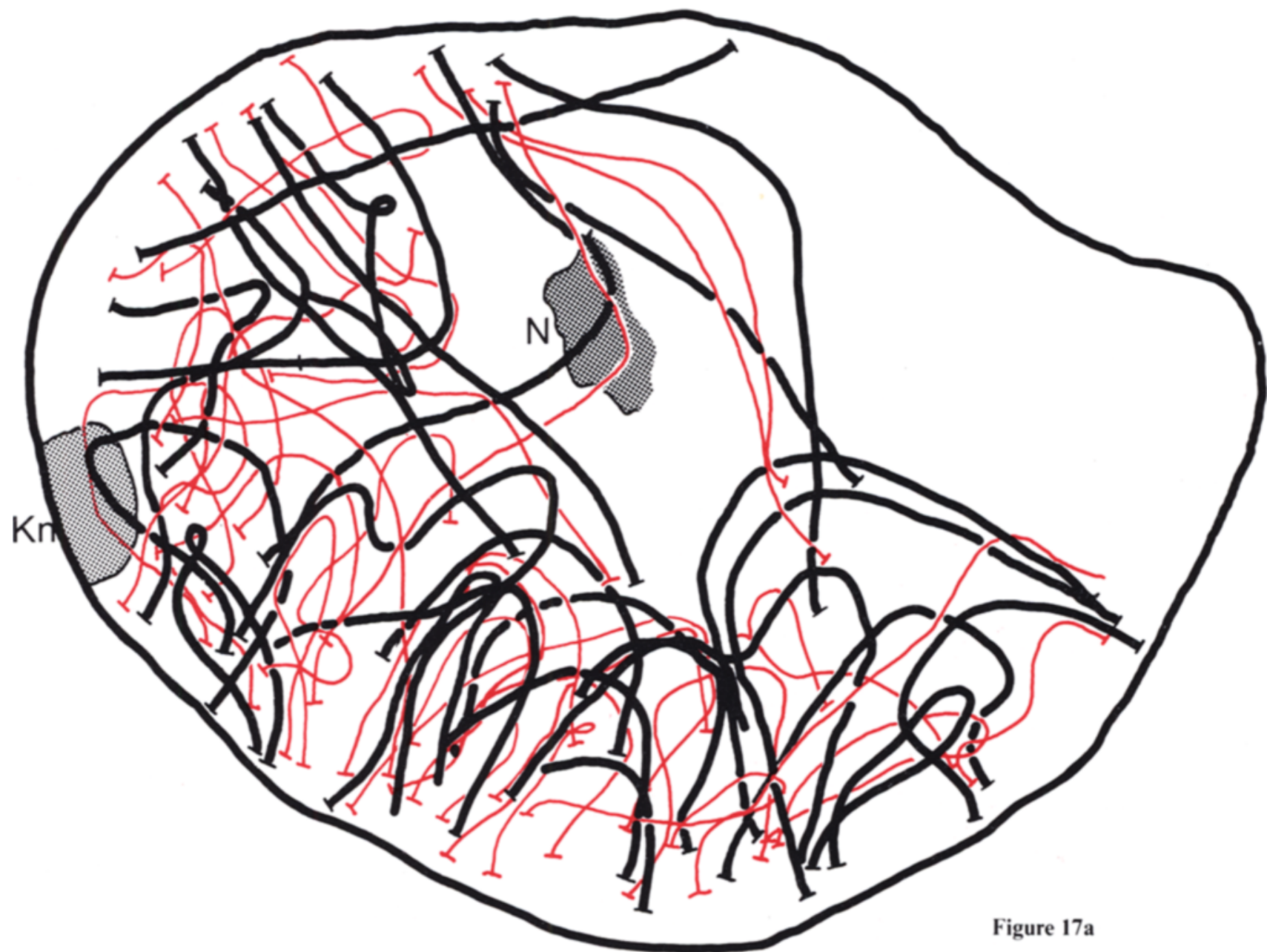

Figure 17a-c. Diagrammatic drawings of complete reconstructions of nuclei 1,4 , and 10 . The black lines represent the synaptonemal complexes and the red lines the unpaired lateral components. The three pictures illustrate the two phases in the dispersal of the chromosome bouquet. In Figure a, both synaptonemal complexes and lateral components have their attachment sites on the nuclear envelope within a limited region. The attachment sites of the synaptonemal complexes in Figure b have shifted so that the paired chromosomes are evenly dispersed throughout the nucleus while about half of the unpaired lateral components are still attached within the bouquet region of the nuclear envelope (the upper left part of Figure b). In Figure c, both synaptonemal complexes and lateral components are evenly distributed in the nucleus.

$\mathrm{Kn}, \mathrm{knob}$. N, nucleolus. 


\section{S. W. Rasmussen: Chromosome pairing in triploid Bombyx mori}

Table Va

Comparison of total synaptonemal complex and lateral component length between nuclei $1-4$ and 5-11.

\begin{tabular}{l|c|c|c}
\hline & $\begin{array}{c}\text { Nuclei } \\
1-4\end{array}$ & $\begin{array}{c}\text { Nuclei } \\
5-11\end{array}$ & t-test \\
\hline $\begin{array}{l}\text { Mean total SC length } \\
\text { Mean total LC length }\end{array}$ & $\begin{array}{l}140 \pm 17 \\
411\end{array}$ & $\begin{array}{l}194 \pm 10 \\
514 \pm 28\end{array}$ & $\mathrm{P}<0.001$ \\
\hline
\end{tabular}

females occurs in two separate phases, one in which homologous pairing is the rule and a second one, in which univalents pair nonhomologously. Between the two phases synaptonemal complexes in trivalents are rearranged to yield homologously paired bivalents and univalents. The first phase or chromosome pairing and synaptonemal complex formation occurs during zygotene and is identical with the pairing in normal diploid organisms. The next phase takes place during early pachytene and corresponds to the non-homologous pairing observed

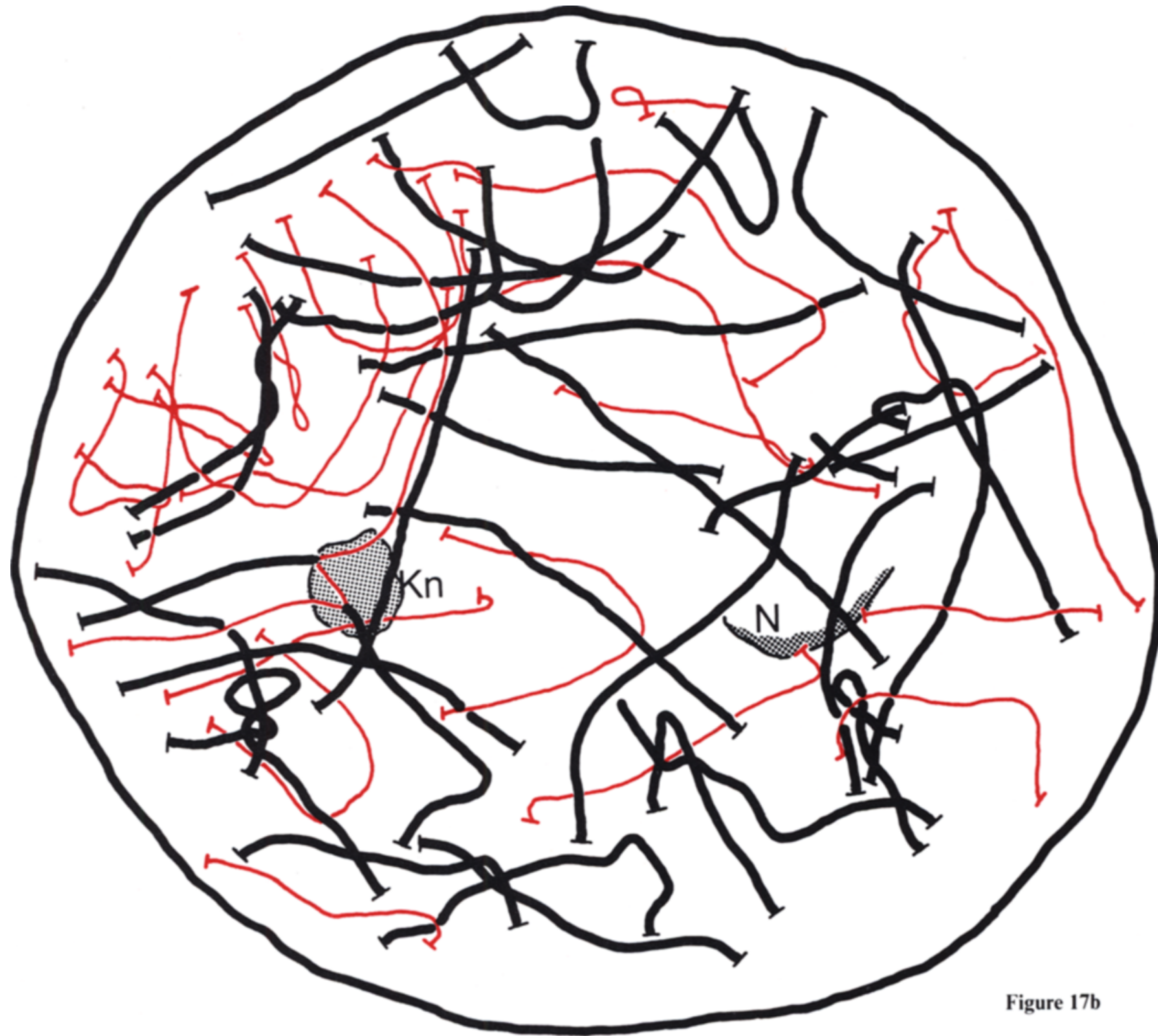


in haploids. Analysis of four diploid nuclei in late zygotene (28, 29, and unpublished results) indicates that the chromosome pairing in nuclei with the diploid chromosome number followed the same scheme. In one of these nuclei, 2 homologous chromosomes were unpaired and were located in separate regions in the nucleus whereas in a second, 2 pairs of homologous chormosomes were completely unpaired. In both nuclei, synaptonemal complex formation was complete in the majority of the bivalents. In the two triploid nuclei at early pachytene, 28 homologous associations were revealed, whereas in 8 of the remaining 9 nuclei analyzed, the number of bivalents is less than the expected 28 for those nuclei with 84 chromosomes (nuclei $3,4,6,7$ ) and less than 31 for those with 87 (nuclei $8,9,11$ ). The pairing of the remaining homologues could have been prevented either by disturbance of the correction of pairing, by the presence of the extra set of chromosomes or as a result of a failure of primary recognition during early zygotene due to the large number of chromosomes in the triploid.

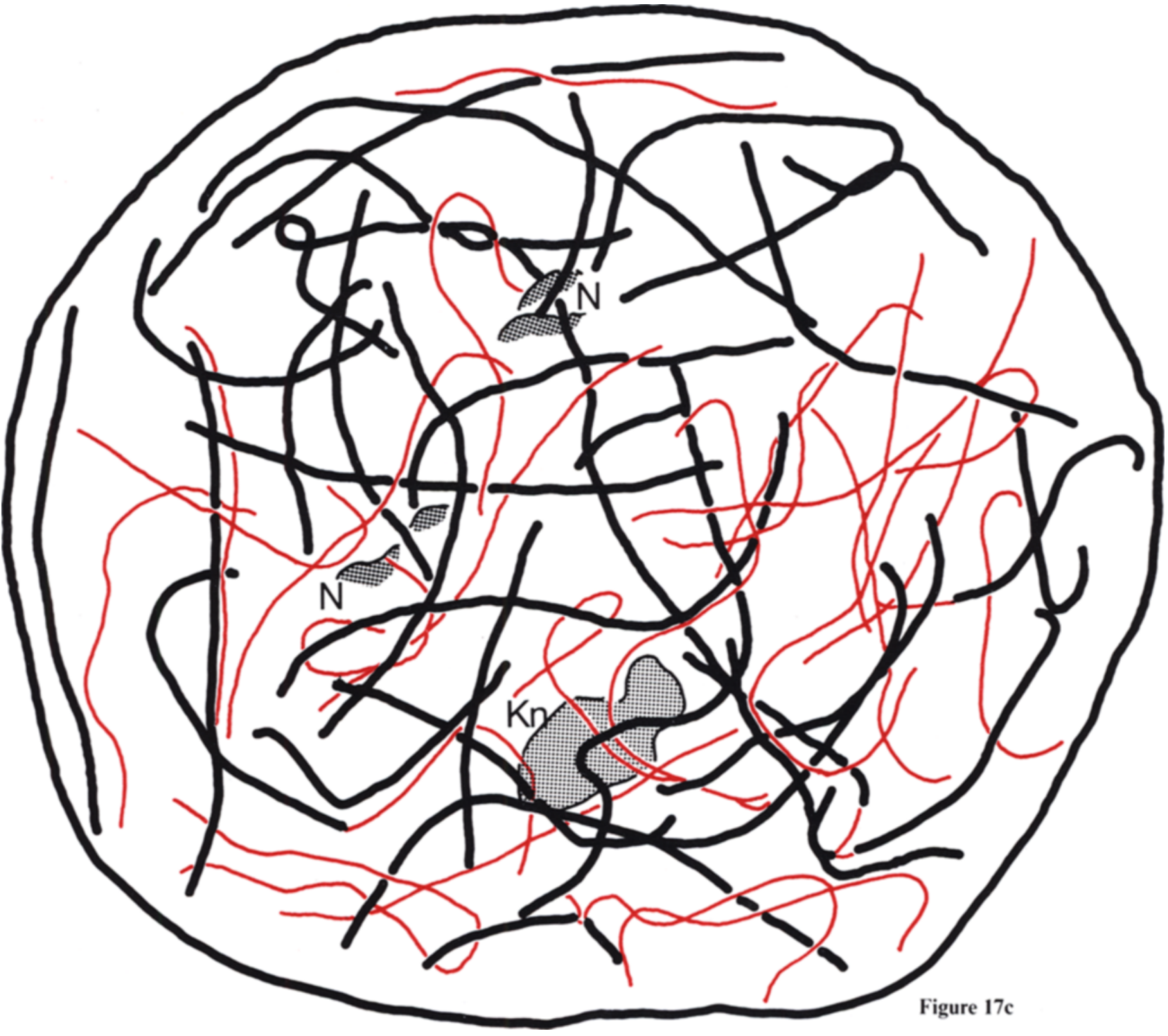


It is likely that the two diploid zygotene nuclei revealed the latter situation. In a diploid Bombyx female, the second round of chromosome pairing with synaptonemal complex formation ensures the completion of the pairing into bivalents, whereas in triploids, the presence of an extra set of chromosomes disturbs the homologous pairing by competing with the homologues in the nonspecific pachytene pairing.

3.6 Variation in chromosome length during pachytene

Two chromosomes can be identified at pachytene in Bombyx mori by morphological markers. Chromosome 1 is identified by a knob which is readily recognized during pachytene. The knob divides the chromosome into two segments with an average ratio of 1:1.8 (Tables VI and VIa). In most nuclei, the synaptonemal complex or lateral component passed uninterrupted through the knob. It was difficult to determine whether the synaptonemal complex or lateral component was continuous through the knob in a few cases because the synaptic structures were obscured by the material of the knob. It is assumed in the calculation of chromosome lengths that the synaptonemal com-

\section{Table VI}

l.ength (in $\mu \mathrm{m}$ ) and segment ratio for chromosomes 1 and 2. Chromosome 1 is divided into two segments by a knob, chromosome 2 by the nucleolus organizer region.

\begin{tabular}{|c|c|c|c|c|c|c|c|c|c|}
\hline \multirow{2}{*}{$\begin{array}{l}\text { Nucleus } \\
\text { number }\end{array}$} & \multicolumn{4}{|c|}{ Chromosome I } & \multicolumn{4}{|c|}{ Chromosome 2a) } & \multirow{2}{*}{$\begin{array}{l}\text { Sum of all } \\
\text { lateral } \\
\text { components }\end{array}$} \\
\hline & & $\begin{array}{c}\text { Absolute } \\
\text { length }\end{array}$ & $\begin{array}{c}\text { Relative } \\
\text { length }\end{array}$ & $\begin{array}{l}\text { Segment } \\
\text { ratio }\end{array}$ & & $\begin{array}{c}\text { Absolute } \\
\text { length }\end{array}$ & $\begin{array}{l}\text { Relative } \\
\text { length }\end{array}$ & $\begin{array}{l}\text { Segment } \\
\text { ratio }\end{array}$ & \\
\hline \multirow[t]{3}{*}{1} & lc & 6.1 c) & 1.6 & 2.0 & Ic & 5.9 & 1.5 & 1.6 & 391 \\
\hline & Ic & 6.7 & 1.7 & 1.5 & & & & & \\
\hline & le & 7.6 & & & & & 1.6 & 1.8 & \\
\hline \multirow[t]{3}{*}{2} & lc & $7.2 \mathrm{cl}$ & 1.9 & 2.1 & lc & $6.2^{c)}$ & 1.6 & 1.1 & 381 \\
\hline & Ic & 7.8 & 2.1 & 2.1 & lc & 6.1 & 1.6 & 1.2 & \\
\hline & $\mathrm{Ic}$ & 7.3 & 1.9 & 2.2 & Ic & 6.1 & 1.6 & 1.8 & \\
\hline \multirow[t]{2}{*}{3} & lc & 7.9 & 2.0 & 1.6 & lc & 8.3 & & & \\
\hline & sc & 7.9 & 2.0 & 1.8 & sc & 8.5 & 2.1 & 1.8 & \\
\hline \multirow[t]{3}{*}{4} & lc & $8.1 \mathrm{c})$ & 1.7 & 1.5 & lc & 9.6 & 2.1 & 2.4 & 470 \\
\hline & lc & 9.0 & 1.9 & 1.7 & & & & & \\
\hline & $1 \mathrm{c}$ & 9.2 & 2.0 & 1.5 & sc & 8.7 & 1.9 & 2.2 & \\
\hline \multirow[t]{2}{*}{5} & lc & 9.6 & 1.8 & 2.0 & Ic & 8.9 & 1.7 & 2.4 & 519 \\
\hline & sc & 10.7 & 2.1 & 1.8 & sc & 8.3 & 1.6 & 2.1 & \\
\hline \multirow[t]{2}{*}{6} & Ic & 10.6 & 1.9 & 1.8 & lc & 8.7 & 1.5 & 1.7 & 569 \\
\hline & sc & 11.3 & 2.0 & 2.1 & sc & 9.0 & 1.6 & 1.8 & \\
\hline \multirow[t]{2}{*}{7} & Ic & 10.1 & 2.1 & 1.9 & $1 \mathrm{c}$ & 8.1 & 1.7 & 1.8 & 487 \\
\hline & sc & 8.5 & 1.8 & 1.7 & sc & 8.9 & 1.8 & 2.0 & \\
\hline \multirow[t]{2}{*}{8} & lc & 7.9 & 1.6 & 1.6 & lc & $9.7 \mathrm{bl}$ & 2.0 & 1.2 & 488 \\
\hline & sc & 9.5 & 1.9 & 1.9 & sc & 7.5 & 1.5 & 2.3 & \\
\hline \multirow[t]{2}{*}{9} & Ic & 8.0 & 1.6 & 1.8 & lc & 7.4 & 1.4 & 2.1 & 515 \\
\hline & sc & 8.9 & 1.7 & 2.0 & sc & 7.5 & 1.5 & 2.3 & \\
\hline \multirow[t]{2}{*}{10} & Ic & 9.4 & 1.9 & 1.7 & $1 \mathrm{c}$ & 10.0 & 2.0 & 1.4 & 498 \\
\hline & sc & 8.9 & 1.8 & 2.0 & sc & 8.2 & 1.7 & 2.0 & \\
\hline \multirow[t]{2}{*}{11} & Ic & 9.3 & $1.8 \mathrm{~b})$ & 1.8 & $1 \mathrm{c}$ & $7.1 \mathrm{c})$ & 1.4 & 1.7 & 519 \\
\hline & sc & 9.7 & 1.9 & 1.6 & $\mathrm{sc}$ & 8.9 & 1.7 & 2.3 & \\
\hline
\end{tabular}

a) the synaptonemal complex or lateral component of chromosome 2 is in most cases discontinuous in the nucleolus organizer region. The length is combined from the lengths of the two segments.

b) non-homologously paired with a different chromosome.

c) trivalent. 
Table VIa.

Comparison of mean length and segment ratio of chromosomes 1 and 2 between nuclei 1-4 and 5-11.

\begin{tabular}{l|c|c|c|c|c|c}
\hline & \multicolumn{2}{|c|}{$\begin{array}{c}\text { Mean length and } \\
\text { standard deviation }\end{array}$} & \multirow{2}{*}{$\mathrm{t}$-test } & \multicolumn{2}{c|}{$\begin{array}{c}\text { Mean segment ratio and } \\
\text { standard deviation }\end{array}$} & t-test \\
\cline { 2 - 3 } & Nuclei 1-4 & Nuclei 5-11 & & Nuclei 1-4 & Nuclei 5-11 & \\
\cline { 2 - 3 } $\begin{array}{l}\text { Lateral component } \\
\text { chromosome 1 }\end{array}$ & $7.7 \pm 1.0$ & $9.3 \pm 1.0$ & $\mathrm{P}<0.001$ & $1.8 \pm 0.3$ & $1.8 \pm 0.1$ & $\mathrm{P}>0.90$ \\
$\begin{array}{l}\text { Lateral component } \\
\text { chromosome 2 }\end{array}$ & $7.1 \pm 1.6$ & $8.5 \pm 1.1$ & $\mathrm{P}<0.001$ & $1.5 \pm 0.5$ & $1.7 \pm 0.4$ & $\mathrm{P}>0.40$ \\
$\begin{array}{l}\text { Synaptonemal com- } \\
\text { plex chromosome 1 }\end{array}$ & $7.9-$ a) & $9.6 \pm 1.0$ & $0.25>\mathrm{P}>0.20 \mathrm{~b})$ & $1.8-$ a) & $1.9 \pm 0.2$ & $\mathrm{P}>0.70$ \\
$\begin{array}{l}\text { Synaptonemal com- } \\
\text { plex chromosome 2 }\end{array}$ & $7.9 \pm 1.3$ & $8.3 \pm 0.6$ & $0.50>\mathrm{P}>0.40 \mathrm{~b})$ & $1.9 \pm 0.3$ & $2.1 \pm 0.2$ & $\mathrm{P}>0.20$ \\
\hline
\end{tabular}

a) only one observation

b) the low number of observations in nuclei $1-4$ possibly accounts for the lack of significance.

plexes and lateral components pass straight through the knob. The other chromosome which can be identified unambiguously was chromosome 2 in which the nucleolus organizer region divided the chromosome into two segments with an average ratio of $1: 1.8$. The synaptonemal complex and the lateral component of chromosome 2 were interrupted at the site of nucleolus attachment in all nuclei analyzed; the distance between the two arms was increasingly larger during pachytene. The interruption of the synaptic strucutres inside the nucleolus was not included in the calculation of chromosome length.

Table VI shows the lengths of the synaptonemal complex and the lateral component, the segment ratios for chromosomes 1 and 2 , and the sum of all paired and unpaired lateral components for each of the 11 nuclei. It appears from Tables VI and VIa that the total length of the lateral components increased from $411 \pm 41 \mu \mathrm{m}$ (average of nuclei 1-4) at the beginning of pachytene to $514 \pm 28 \mu \mathrm{m}$ (average of nuclei 5-11) towards the end of pachytene.

The total lengths of all lateral components differed considerably in the 11 nuclei (Table $\mathrm{V}$ and $\mathrm{Va}$ ); nucleus 6 had the greatest total length of lateral components, being about $50 \%$ greater than that of nucleus 1 . It is uncertain whether the $25 \%$ increase in mean lateral component length from early to mid pachytene is due to the presence of an extra genome or is a normal feature of development. A less drastic rise in synaptonemal complex length was observed in 4 zygotene and 6 pachytene nuclei from diploid females previously analyzed. The average diploid zygotene length was $195 \pm 8 \mu \mathrm{m}$ and the pachytene length $212 \pm 7 \mu \mathrm{m}(28,29$ and unpublished results). A comparison of the two means with a t-test gave a $P$ value between 0.1 and 0.05 . The difference is thus not significant.

The data in Table VI also show for some of the nuclei a rough relationship between the length of the synaptonemal complex or the lateral component of chromosomes 1 and 2 and the sum of all lateral components (including those which are paired into synaptonemal complexes). If the total lengths of all lateral components were small, the lengths of the synaptonemal complexes and lateral components of chromosomes 1 and 2 were also small. Compare for example the lengths of chromosomes 1 and 2 in nuclei 1 and 2 with nucleus 6 . In several cases though, the opposite situation was encountered: Nucleus 3 has a total lateral component length of $401 \mu \mathrm{m}$ and a lateral component 
length for chromosomes 1 and 2 of $7.9 \mu \mathrm{m}$ and $8.3 \mu \mathrm{m}$ respectively, whereas the total lateral component length of nucleus 9 is $516 \mu \mathrm{m}$ with a lateral component length for chromosomes 1 and 2 of $8.9 \mu \mathrm{m}$ and $7.5 \mu \mathrm{m}$ respectively, i.e., the $29 \%$ difference in total lateral component length between the two nuclei is not reflected in the lengths of chromosomes 1 and 2.

When the segment ratios for each of the two chromosomes were compared in the 11 nuclei an even greater variation in length of synaptonemal complexes and lateral components was observed. The arm ratio for chromosome 1 varies between $1: 1.5$ and $1: 22$, and for chromosome 2, between 1:1.1 and 1:2.4 (Table VI). On the other hand, a comparison of the segment ratios between nuclei 1-4 (early to mid pachytene) and nuclei 5-11 (mid to late pachytene) of chromosomes 1 and 2 showed no significant differences between the segment ratios of univalents and bivalents (Table VIa).

As indicated by the data in Table IV, the synaptonemal complex length of a bivalent was generally longer than the lateral component length of its homologous univalent, the ratio of synaptonemal complex length to lateral component length being $1.1 \pm 0.1$ in nuclei 1 and 2 . This suggests that lateral components are stretched as a result of their pairing into synaptonemal complexes.

\section{DISCUSSION}

\subsection{Determination of a temporal sequence in nu- clear development}

The transition from zygotene to pachytene is characterized by the chromosome bouquet, the association of the three homologues, and bivalents or bivalent segments with completed synaptonemal complexes. At early pachytene the bouquet is dissolved and the third homologue separates from its bivalent. At mid to late pachytene the telomeres detach from the nuclear envelope and, towards the end of the stage, the chromosomes are uniformly distributed in the nucleoplasm (28). This study examined 11 nuclei during this period of meiotic prophase. Some temporal changes are thus seen in greater detail, such as variations in the number and position of nuclear vacuoles, the morphology and spatial arrangement of chromosomes, and the pairing of the lateral components into synaptonemal complexes. The changes in these nuclear components are synchronous only to a limited extent in a nucleus.

\subsection{Specificity of chromosome pairing}

Generally, studies on chromosome pairing in a wide range of normal diploid organisms provide evidence in favour of a high degree of regularity in the pairing of homologous chromosomes into bivalents with the aid of the synaptonemal complex. (See WESTERGAARD and von WeTtSTEIN, 54, Gillies, 9 for general reviews.) Data based on complete serial reconstructions are available in Zea mays (7), yeast (2), Neurospora (6), Ascaris (12), Bombyx (28), and Sordaria (56) among others. The expected number of bivalents with synaptonemal complexes spanning the distance between the attachment sites on the nuclear envelope is regularly found thus indicating a perfect homologous pairing. Several cases are known however, where extensive chromosome pairing with synaptonemal complexes occurs between apparently non-homologous chromosome segments. Synaptonemal complexes are readily observed in haploid maize $(46,47)$, barley $(8)$, Petunia and Antirrhinum (36), and tomato (18). In haploid barley, up to $60 \%$ of the lateral component length is paired into synaptonemal complexes, which are morphologically indistinguishable from complexes between homologous chromosomes (8). In hybrids between tomato and Solanum, synaptonemal complexes are formed between homoeologous chromosomes, the pairing considered to be primarily non-homologous (18). Gillies $(7,10)$ also described in Zea mays a possible non-homologous foldback pairing in nuclei heterozygous for an abnormal chromosome 10, K10. (K10 has an extra chromosome segment attached to the long arm of the normal chromosome 10.). Furthermore, the nature of the pairing in reconstructed nuclei heterozygous for an inversion on chromosome 3 is dependent on whether the abnormal chromosome 10 is present or not. The inverted segment is frequently unpaired in the absence of K10, whereas in the presence of $\mathrm{K} 10$ the inverted segment is paired either into a typical inversion 
loop, or non-homologously paired with its synaptonemal complex continuous with complexes of the adjacent chromosome segments. The latter two situations were found with equal frequency. A similar situation was reported by SOLARI (38) in mice carrying Searle's translocation, the pairing being primarily homologous in the translocated region giving rise to a quadrivalent (with two autosomes, the $\mathrm{X}$ chromosome, and $\mathrm{Y}$ chromosome). In 50\% of the nuclei analyzed, however, a segment of the $X$ chromosome formed a synaptonemal complex with a segment of one of the autosomes.

It thus appears that intimate chromosome pairing mediated by the synaptonemal complex occurs preferentially between homologous chromosome segments; but in the absence of a homologous pairing partner, or if the homologous matching is impeded by structural rearrangements of one or more chromosomes, the synaptonemal complex is also formed between non-homologous chromosome segments.

The distinction between homologous and non-homologous pairing is particularly clear in triploid organisms, where homologous and nonhomologous pairing can be compared in the same nucleus. Previous work on triploid Lilium $(22,24)$, Allium (40) and chickens (4) has revealed two characteristics of pairing in triploids which may also be relevant to chromosome pairing in normal diploids: The association of the three homologues with a synaptonemal complex between two of the three lateral components at any place along the chromosome and the short stretches of "double" synaptonemal complex which were observed near the attachment sites of the lateral complexes on the nuclear envelope in triploid chickens (4). Chromosome pairing in triploid females of Drosophila constitutes an exception, as lateral components were only present in the two chromosomes paired by synaptonemal complexes and absent in the third homologue (19).

At the start of the transition from zygotene to pachytene in triploid Bombyx females, the majority of chromosomes are roughly paired in sets of three, two of the chromosomes having a complete synaptonemal complex and the third lying parallel at some distance. The presence of the double complex near the nuclear envelope in Bombyx shows that a second central region can temporarily attach to a normal complex in a lateral position and combine with the third lateral component. This provides additional evidence that synaptonemal complex formation in Bombyx starts exclusively from the attachment sites on the nuclear envelope. These observations are in agreement with earlier reports $(4,40)$. Zygotene pairing is initiated by the alignment of homologues and requires that the chromosome segments to be paired should be homologous. This first pairing phase thus constitutes the main period for homologous chromosome pairing in diploid organisms and includes cases in which rearranged chromosomes pair homologously (e.g., heterozygous inversions in maize, GiLLIES, 7, 10). A complete serial reconstruction of the very long chromosome in an early zygotene nucleus of Lilium, with about $25 \%$ of the lateral components combined into synaptonemal complexes, illustrates the preponderance of homologous chromosome pairing during zygotene. Only very short stretches that might possibly be non-homologously paired chromosome segments were found (15).

The remarkable decrease in the number of trivalents after the start of pachytene in triploid Bombyx, together with the observation that the short stretches of double complex disappear in regions near the nuclear envelope, provides support for the previously postulated mechanism (28) for correction of incompletely paired chromosomes. The conversion of trivalents into bivalents and univalents requires the dissolution of the synaptonemal complex and its reformation between two different lateral components.

After the attraction of homologous chromosomes ceases, the remaining non-homologous chromosome segments form synaptonemal complexes. The extent of this second non-homologous pairing depends upon the degree of synaptonemal complex formation which has been achieved by the preceding homologous pairing.

In haploid nuclei chromosome pairing is of the second, non-homologous type, and probably dependent in extent on the proximity of two initiation points for complex formation, one on each of the two lateral components. In hybrids 
where the two sets of chromosomes have approximately the same length and contain sizeable homologous segments, the pairing could be as complete as in normal diploids (18). Pairing can be initiated with the homologous segments and completed by the unspecific nonhomologous formation of complexes.

Further exepriments are required before the differences in behaviour of the meiotic chromosomes between triploid Solenobia and triploid Bombyx can be explained (see SEILER, 35, ASTAUROV, 1, VEREISKAYA, 49, and KaWAGUCHI, cited from TAzima, 45). The observation that in triploid Solenobia the three homologues remain associated until anaphase 1 (35) suggests a temporal sequence of events in zygotene and pachytene different from that observed in triploid Bombyx (45). It is likely that a modification of synaptonemal complexes similar to that of female Bombyx (28) occurs in Solenobia. In triploid Solenobia, the modification may take place at a time when the three homologues are associated and thereby preserves the association of homologues until "chromatin elimination" and disjunction occur in anaphase 1. Predominantly female intersexes of triploid Solenobia are able to produce eggs which can develop parthenogenetically by a fusion of the nucleus resulting from the second polar nucleus with the daughter nucleus of the first polar nucleus ('Richtungskopulationskern") whereby the triploid chromosome number is re-established.

A different way of preserving the triploid chromosome number is observed in parthenogenetic Otiorrhynchus (34), where the first meiotic division is rudimentary and the triploid female thus fully fertile. Also the sex differences in fertility of male and female tetraploid Bombyx need further clarification. Especially the determination of the exact time of crossing over is essential for understanding the reported differences in the number of chromosome elements at metaphase 1 (56 elements in females and less than 56 in males) (50). It is possible that crossing over in tetraploid Bombyx males protects the synaptonemal complex from being corrected at early zygotene or alternatively, that the aberrant chromosome associations observed at metaphase I are formed in the second round of pairing and subsequently preserved until metaphase I by crossing over and chiasma formation.

On the basis of cytological and genetic studies of chromosome pairing in hexaploid Triticum, Riley and ChapMan (31), Riley et al. (32), Mello-Sampayo (17), and Feldman (5) concluded that the amount of homoeologous pairing between genetically equivalent chromosomes from different species is inhibited by one or several genes located on the long arm of chromosome 5B. Later, Mello-Sampayo (17) demonstrated that a gene with a similar effect was present on chromosome $3 \mathrm{D}$ and arrived at the same conclusion as Riley and FELDMAN, namely that the primary function of these genes is to inhibit non-homologous pairing. In the absence of the short arm of chromosome 5B, a decrease in synapsis is accompanied by an increase in homoeological pairing and chromosome interlockings. In the light of the results presented in this report, it is conceivable that instead of an inhibition of non-homologus (homoelogical) pairing, the genes on chromosome 5B may promote homologous chromosome pairing during zygotene, so that at the onset of pachytene, only a few or no unpaired chromosomes remain. Alternatively, the genes on chromosome 5B may extend the requirement for homology of the chromosomes to be paired into the second pairing phase. The result in both cases is increased homologous pairing. The increase in non-homologous pairing and in the number of chromosome interlockings observed in the absence of the short arm of chromosome $5 B(5)$, may be explained as the result of a deficient system for correction of chromosome pairing.

The present results may also be relevant to the interpretation of the two types of chromosome pairing in Drosophila which have been demonstrated by GRELL $(13,14)$ on the basis of chromosome disjunction in situations where extra chromosomes or chromosome segments are present. The "exchange" pairing which is suggested to involve homologous chromosomes only and the subsequent "distributive" pairing which may involve homologous as well as nonhomologous chromosome segments, might thus be a reflection of the two phases (the homolo- 
gous and non-homolous phases) of chromosome pairing and of synaptonemal complex formation as described in the present report.

\section{ACKNOWLEDGEMENT}

It is a pleasure to acknowledge the generous help and advice of the late Prof. B. L. ASTAURov, Institute of Developmental Biology, Academy of Sciences USSR, Moscow. I also wish to thank Prof. D. von WeTtstein, cand.scient Preben B. Holm, and Dr. DAvid SIMPSON for valuable discussions and criticism. I especially thank JEAN SAGE for outstanding technical assistance. Finally, the assistance of Nina Rasmussen, AnN-Sofi Steinholtz, and SHIRLEY MOGENSEN is gratefully acknowledged. The work was supported by grant GM22051 of the National Institute of Health (USPHS) to Prof. D. von WeTTSTEIN, by Nato Research Grant 1061, and by the cultural exchange program between USSR and Denmark.

\section{REFERENCES}

1. Astaurov, B. L.: Experimental alterations of the developmental cytogenetic mechanisms in mulberry silkworms: Artificial parthenogenesis, polyploidy gynogenesis, and androgenesis. Adv. Morphogenesis 6, 199-253 (1967)

2. BEYERS, B. \& L. GoETSCH: Electron microscopic observations on the meiotic karyotype of diploid and tetraploid Saccharomyces cerevisiae. Proc. Nat. Acad. Sci. USA 72, 5056-5060(1975)

3. Carpenter, A. T. C.: Electron microscopy of meiosis in Drosophila melanogaster females: II: The recombination nodule - a recombination-associated structure at pachytene? Proc. Nat. Acad. Sci. USA 72, 3186-3189(1975)

4. Comings, D. E. \& T. A. OKada: Triple chromosome pairing in triploid chickens. Nature 231, 119-121 (1971)

5. Feldman, M.: The effect of chromosomes 5B, 5D, and 5A on chromosomal pairing in Triticum aestivum. Proc. Nat. Acad. Sci. USA 55, 1447 1453 (1966)

6. GILLIES, C. B.: Reconstruction of the Neurospora crassa pachytene karyotype from serial sections of synaptonemal complexes. Chromosoma (Berl.) $36,119-130$ (1972)

7. Giluies, C. B.: Ultrastructural analysis of maize pachytene karyotypes by three dimensional re- constructions of the synaptonemal complexes. Chromosoma (Berl.) 43, 145-176 (1973)

8. Gillies, C. B.: The nature and extent of synaptonemal complex formation in haploid barley. Chromosoma (Berl.) 48, 441-453 (1974)

9. Gillies, C. B.: Synaptonemal complex and chromosome structure. Ann. Rev. Genet. 9, 91-109 (1975)

10. Giluies, C.B.: An ultrastructural analysis of chromosomal pairing in maize. C. R. Trav. Lab. Carlsberg 40, 135-161 (1975)

11. Gillies, C. B., S. W. Rasmussen \& D. von WETTSTEIN: The synaptinemal complex in homologous and nonhomologous pairing of chromosomes. Cold Spr. Harb. Symp. quant. Biol. 38, 117122 (1973)

12. Goldstein, P. \& P. B. Moens: Karyotype analysis of Ascaris lumbricoides var. suum. Chromosoma (Berl.) 58, 101-111 (1976)

13. GRELL, R. F.: Non random assortment of non-homologous chromosomes in Drosophila melanogaster. Genetics 44, 421-435 (1959)

14. Grell, R. F.: A new hypothesis on the nature and sequence of meiotic events in the female of Drosophila melanogaster. Proc. Nat. Acad. Sci. USA 48, 165-172 (1962)

15. Holm, P. B.: Three dimensional reconstruction of chromosome pairing during the zygotene stage of meiosis in Lilium longiflorum (Thunb.). Carisberg Res. Commun. 42, 103-151 (1977)

16. KING, R. C. \& H. AKaI: Spermatogenesis in Bombyx mori. II. The ultrastructure of synapsed bivalents. J. Morph. 134. 181-194 (1971)

17. Mello-Sampayo, T.: Genetic regulation of meiotic chromosome pairing by chromosome 3D of Triticum aestivum. Nature New Biol. 230, 22-23 (1971)

18. Menzel, M. Y. \& J. M. Price: Fine structure of synapsed chromosomes in $F_{1}$ Lycopersicon esculentum - Solanum lycopersicoides and its parents. Amer. J. Bot. 53, 1079-1086 (1966)

19. MEYER, G. F.: A possible correlation between the submicroscopic structure of meiotic chromosomes and crossing over. Proc. 3rd Europ. Reg. Conf. E. M. Prague B pp 461-462 (1964)

20. Miya, K., M. Kurihara, \& J. Tanimura: Electron microscope studies on the oogenesis of the silkworm Bombyx mori L. III. J. Fac. Agric. Iwate Univ. 10, 59-83 (1970)

21. MoENs, P. B.: The fine structure of meiotic chromosome pairing in Locusta migratoria spermatocytes. Chromosoma (Berl.) 28, 1-25 (1969)

22. MoENS, P. B.: The fine structure of meiotic chromosome pairing in the triploid, Lilium tigrinum. J. Cell Biol. 40, 273-279 (1969) 
23. Moens, P. B.: Multiple core complexes in grasshopper spermatocytes and spematids. J. Cell Biol. 40, 542.551 (1969)

24. Moens, P. B.: The fine structure of meiotic chromosome pairing in natural and artificial Lilium polyploids. J. Cell Sci. 7, 55-63 (1970)

25. Moens, P. B.: Quantitative electron microscopy of chromosome organization at meiotic prophase. Cold Spr. Harb. Symp. quant. Biol. 38, 99-107 (1973)

26. Murakami, A. \& H. T. Imat: Cytological evidence for holocentric chromosomes of the silkworm, Bombyx mori and Bombyx mandarina (Bombycidae, Lepidoptera) Chromosoma (Berl.) 47, 167 178 (1974)

27. Rasmussen, S. W.: Studies on the development of the synaptonemal complex in Drosophila melanogaster. C. R. Trav. Lab. Carlsberg 39, 443-468 (1974)

28. Rasmussen, S. W.: The meiotic prophase in Bombyx mori females analyzed by three-dimensional reconstructions of synaptonemal complexes. Chromosoma (Berl.) 54, 245-293 (1976)

29. Rasmussen, S. W.: Meiosis in Bombyx mori females. Phil. Trans. R. Soc. Lond. B. 277, 343-350 (1977)

30. Rasmussen, S. W.: The transformation of the synaptonemal complex into the "elimination chromatin" in Bombyx mori oocytes. Chromosoma (Berl.), 60, 205-221 (1977)

31. Riley, R. \& V. Chapman: Genetic control of the cytologically diploid behaviour of hexaploid wheat. Nature 182,713-715 (1958)

32. Ruley, R. V. Chapman, R. M. Young, \& A. M. BELFIELD: Control of meiotic chromosome pairing by the chromosomes of homoeologous group 5 of iriticum aestivum. Nature 212, 1475 1477 (1966)

33. Rossen, J. M. \& M. WestergaARd: Studies on the mechanism of crossing over II. Meiosis and the time of meiotic chromosome replication in the ascomycete Neottiella rutilans (Fr) Dennis. C. R. Trav. Lab. Carlsberg 35, 233-260 (1966)

34. SeILer, J.: Die Zytologie eines Parthenogenetischen Rüsselkäfers, Otiorrhynchus sulcatus $F$. Chromosoma (Berl.) 3, 88-109 (1947)

35. SeILER, J.: Die Zytologie der Bastarde aus der Kreuzung Parthenogenetische Weibchen von Solenobia triquetrella F. R. mit Männchen der Bisexuellen Rasse. I. Mitteilung. Chromosoma (Berl.) 19, 405-438 (1966)

36. SEN, S. K.: Synaptonemal complexes in haploid Petunia and Antirrhinum sp., Naturwissenschaften $57,550(1970)$
37. Solari, A. J.: The behaviour of chromosomal axes during diplotene in mouse spermatocytes. Chromosoma (Berl.) 31, 217-230 (1970)

38. SolARI, A. J.: The behaviour of chromosomal axes in Searle's X-autosome translocation. Chromosoma (Berl.) 34, 99-112(1971)

39. Sotelo, J. R., R. B. Garcia \& R. Wettstein: Serial sectioning study of some meiotic stages in Scaptericus borrelli (Grylloidea). Chromosoma (Berl.) 42, 307-333 (1973)

40. Stack, S.: The synaptonemal complex and the achiasmatic condition. J. Cell Sci. 13, 83-95 (1973)

41. StERN, H. \& Y. Hotta: Biochemical controls of meiosis. Ann. Rev. Genet. 7, 37-66 (1974)

42. Sturtevant, A. H.: No crossing over in the female of the silkworm moth. Amer. Naturalist 49, 4244 (1915)

43. TANAKA, Y.: A study of mendelian factors in the silkworm, Bombyx mori. J. Coll. Agric. Sapporo 5, 61-113(1913)

44. TANAKA, Y.: Gametic coupling and repulsion in silkworms. J. Coll. Agric. Sapporo 5, 115-148 (1913)

45. TAzImA, Y.: The genetics of the silkworm. London: Academic Press Logos Press (1964)

46. TING, Y. C.: Fine structure of the meiotic first prophase chromosomes in haploid and diploid maize. Genetics 61, s58 (1969)

47. TING, Y. C.: Synaptonemal complex and crossing over in haploid maize. In: Chromosomes Today, J. Wahrman and K. R. Lewis, eds., John Wiley \& Sons, New York, and Israel Universities Press, Jerusalem, Vol. IV pp. 161-167 (1973)

48. Traut, W.: Pachytene mapping in the female silkworm, Bombyx mori L. (Lepidoptera). Chromosoma (Berl.) 58, 275-284 (1976)

49. VereisKaya, V. N.: Meiosis in thermoactivated oocytes of Bombyx mori L. Ontogenez (Moscow) 4, 623-627 (1973)

50. Vereiskaya, V. N. \& T. A. Vininik: Meiosis in thermoactivated oocytes of Bombyx mori L. 1 . Tetraploids. Ontogenez (Moscow) 4, 139-144 (1973)

51. Welsch, B.: Synaptonemal Complex and Chromosomenstruktur in der achiasmatischen Spermatogenese von Panorpa communis (Mecoptera). Chromosoma (Berl.) 43, 19.74 (1973)

52. WestergaArd, M. \& D. von Wettstein: The meiotic cycle in an ascomycete. In: "Effects of Radiation on Meiotic Systems". Int. Atom. Energy Agency Vienna. Panel Proc. Ser. Sti/Pub/173, 113-121 (1968) 
S. W. RASMUSSEN: Chromosome pairing in triploid Bombyx mori

53. WestergaARd M. \& D. von Wettstein: Studies on the mechanism of crossing over. IV. The molecular organization of the synaptinemal complex in Neottiella (Cooke) Saccardo (Ascomycetes) C. R. Trav. Lab. Carlsberg 37, 239-268 (1970)

54. WestergaARD, M. \& D. von Wettstein: The synaptonemal complex. Ann. Rev. Genet. 6, 71$110(1972)$
55. WeTtSTEIN, D. von: The assembly of the synaptinemal complex. Phil. Trans. R. Soc. Lond. B., 277, 235-243 (1977)

56. ZICKLER, D.: Development of the synaptonemal complex and the "recombination-nodules" during meiotic prophase in the seven bivalents of the fungus Sordaria macrospora Auersw. Chromosoma (Berl.) In press (1977) 